\title{
Linking individual and population patterns of rocky-shore mussels
}

\author{
Romina Vanessa Barbosa ${ }^{\text {Corresp., }}{ }^{1}$, Cédric Bacher ${ }^{2}$, Frédéric Jean ${ }^{1}$, Yoann Thomas ${ }^{1}$ \\ 1 Univ Brest, CNRS, IRD, Ifremer, LEMAR, F-29280, Plouzané, France \\ 2 Ifremer, DYNECO, F-29280, Plouzané, France \\ Corresponding Author: Romina Vanessa Barbosa \\ Email address: rominavanessa.barbosa@univ-brest.fr
}

Individual traits and population parameters can be used as proxies of processes taking place within a range of scales, thus improving the way we can evaluate species response to environmental variability. In intertidal rocky shores, patterns at the within-site scale, i.e., between centimeters to hundreds of meters, are important for understanding the population response into these highly variable environments. Here, we studied a rockyshore mussel population at the within-site spatial scale (1) to test how intertidal height and orientation of the shore affect individual traits and population parameters, (2) to infer the link between individual and population level features, and (3) to explore the upscaling mechanisms driving population structure and processes. We analyzed the patterns of six population parameters: density, biomass, crowding, median individual size, recruitment and mortality rate, and four individual traits: growth rate, spawning phenology, size and condition index. Crowding was defined as the degree of overlapping of individuals within a given area, for which we created a "crowding index". Mussels were studied along the intertidal height gradient in two rocky shores with contrasted orientation at one site over a full year. Our results showed a significant effect of intertidal height and shore orientation on most of individual traits and population parameters studied. In contrast, biomass contained in a full covered surface did not vary in space nor in time. This pattern likely results from relatively constant crowding and a trade-off between median individuals' size and density. We hypothesize that growth, mortality and recruitment rates may all play roles in the stability of the crowding structure of mussel aggregations. Variation in spawning phenology between the two shores in the study site was also observed, suggesting different temporal dynamics of microclimate conditions. Interestingly, despite the different population size distribution between the two shores, our estimates indicate similar potential reproductive output. We hypothesize that the structure of the patches would tend to maintain or carry a maximum of biomass due to trade-offs between density and size while maintaining and maximizing the reproductive output. The patterns of spatial 
variability of individual traits and population parameters in our study site suggest that heterogeneous within-site conditions influence variation in individual performance and population processes. These results provide insights about the relationship between individual traits and how these relationships make patterns at the population level emerge. They provide baseline information necessary to improve models of metapopulation with spatially explicit processes. 
1 Linking individual and population patterns of rocky2 shore mussels

3

4

5

6

\author{
Romina Vanessa Barbosa ${ }^{1}$, Cédric Bacher ${ }^{2}$, Frédéric Jean ${ }^{1}$, Yoann Thomas ${ }^{1}$ \\ ${ }^{1}$ Univ Brest, CNRS, IRD, Ifremer, LEMAR, F-29280 Plouzané, France \\ ${ }^{2}$ Ifremer, DYNECO, F-29280 Plouzané, France \\ Corresponding Author: \\ Romina Barbosa \\ Rue Dumont d'Urville, 29280 Plouzané, France \\ Email address: rominavanessa.barbosa@univ-brest.fr
}

\title{
Abstract
}

Individual traits and population parameters can be used as proxies of processes taking place within a range of scales, thus improving the way we can evaluate species response to environmental variability. In intertidal rocky shores, patterns at the within-site scale, i.e., between centimeters to hundreds of meters, are important for understanding the population response into these highly variable environments. Here, we studied a rocky-shore mussel population at the within-site spatial scale (1) to test how intertidal height and orientation of the shore affect individual traits and population parameters, (2) to infer the link between individual and population level features and (3) to explore the upscaling mechanisms driving population structure and processes. We analyzed the patterns of six population parameters: density, biomass, crowding, median individual size, recruitment and mortality rate, and four individual traits: growth rate, spawning phenology, size and condition index. Crowding was defined as the degree of overlapping of individuals within a given area, for which we created a "crowding index". Mussels were studied along the intertidal height gradient in two rocky shores with contrasted orientation at one site over a full year. Our results showed a significant effect of intertidal height and shore orientation on most of individual traits and population parameters studied. In contrast, biomass contained in a full covered surface did not vary in space nor in time. This pattern likely results from relatively constant crowding and a trade-off between median individuals' size and density. We hypothesize that growth, mortality and recruitment rates may all play roles in the stability of the crowding structure of mussel aggregations. Variation in spawning phenology between the two shores in the study site was also observed, suggesting different temporal dynamics of microclimate conditions. Interestingly, despite the different population size distribution between the two shores, our estimates indicate similar potential reproductive output. We hypothesize that the structure of the patches would tend to maintain or carry a maximum of biomass due to trade-offs between density and size while maintaining and maximizing the reproductive output. The patterns of spatial variability of individual traits and population parameters in our study site suggest that heterogeneous within-site conditions influence variation in individual performance and population processes. These results provide insights about the 
41

42

43

44

45

46

47

48

49

50

51

52

53

54

55

56

57

58

59

60

61

62

63

64

65

66

67

68

69

70

71

72

73

74

75

76

77

78

79

80

relationship between individual traits and how these relationships make patterns at the population level emerge. They provide baseline information necessary to improve models of metapopulation with spatially explicit processes.

\section{Introduction}

For marine species living in intertidal zones of rocky shores, environmental conditions vary from centimeters to hundreds of meters depending on habitat structure. These conditions determine population responses through the metabolic processes, behavior, fitness and survival of individuals. For macrotidal ecosystems, the intertidal height creates a gradient of environmental conditions related to the aerial exposure of individuals, which increases from low to high elevation. Consequently, temperature varies according to the intertidal height, with higher daily average maximum at higher intertidal height (Helmuth et al., 2011). Temperatures also vary daily, depending on topographic features (Denny et al., 2011; Seabra et al., 2011; Dong et al., 2017; Miller \& Dowd, 2019; Wang et al., 2020), which creates microclimates (Helmuth et al. 2006; Choi et al., 2019). The mosaic of microclimates on a site can represent higher environmental variability than latitudinal mean temperature comparisons (Denny et al. 2011; Seabra et al., 2011). Therefore, evaluating individual variability and population response at the within-site scale (i.e., from centimeters to hundreds of meters) could improve comprehension and forecasting of population dynamics at higher scales.

A diversity of species is adapted to living in highly heterogeneous rocky-shore habitats, mussels being among the most important (Paine, 1971; Paine, 1974; Menge, 1976). Mussels are engineer species that create habitat for other species (Borthagaray \& Carranza, 2007; Arribas et al., 2014) with a wide distribution. The strategy used by mussels such as Mytilus spp. to dominate the intertidal space is aggregative behavior (Bertness \& Grosholz, 1985). Their aggregation structure can be characterized in terms of crowding - how close are individuals - and number of layers (e.g., Guiñez, Castilla \& Sterner, 1999), features that vary between sites and species, and have been related to environmental conditions and species mobility capacity (Commito \& Rusignuolo, 2000; Gutierrez et al., 2015; de Jager et al., 2020; Zardi et al., 2021). Mussel aggregation structure conditions the development and survival of young mussels, by increasing survival of recruits living between aggregated adults (Bertolini, Montgomery \& O'Connor, 2018). It also conditions the stability of entire patches, since it could affect the resistance to dislodgement (Denny, 1987; Gutierrez et al. 2015; Zardi et al., 2021). Aggregation structure is, therefore, fundamental for the persistence of the population in diverse conditions.

Features of individual mussels and mussel populations have been more frequently examined at regional or latitudinal scales than at the within-site scale. For instance, mussel density and area covered vary between sites and according to intertidal height distribution as a result of complex mechanisms linked to environmental conditions and biotic interactions (Blanchette \& Gaines, 2007). Mussel populations also present variation of mean individual size and abundance associated with different growth, likely driven by environmental factors such as food availability, wave exposure and temperature (Blanchette, Helmuth \& Gaines, 2007; Blanchette \& Gaines, 
81

82

83

84

85

86

87

88

89

90

91

92

93

94

95

96

97

98

99

100

101

102

103

104

105

106

107

108

109

110

111

112

113

114

115

116

117

118

119

2007; Fitzgerald-Dehoog, Browning \& Allen, 2012; Gomez et al., 2018). In the intertidal zone of macrotidal areas, the above-described variability of environmental conditions likely determines the performance of individuals across the intertidal height and depending on the angle of orientation of their rocky substrate. Such variability has been observed at latitudinal scales covering a wide area, but scarce information exists about this kind of patterns at within-site scale.

Monitoring environmental conditions and their relationship with individual response at smallscale across a complete study area remains challenging. We propose to use individual traits and populations parameters as proxies of performance to fill the actual knowledge gap and test new hypothesis. Evaluating patterns of individual traits and population parameters at different hierarchical levels and scales (spatial or temporal) is an important way to infer possible underlying mechanisms (Grimm et al., 2005). Any observation presenting a non-random structure, such as the observed structure of individual's disposition in the space (e.g., patches, uniform, etc.) or the temporal dynamics of individual traits (e.g., phenology of reproduction) constitutes a "pattern". For instance, the aggregation pattern is likely driven by mechanisms of inter-individual interaction and environmental stress (van de Koppel et al., 2008; de Jager et al., 2011, 2020).

In this study, we aimed to study a rocky-shore mussel population at the within-site spatial scale. We hypothesized that the intertidal height and the main orientation of the shore create patterns of traits distribution. Given the hydrodynamics and mixing of the water column at within-site scale, we assumed that all other environmental variables such as food or salinity were spatially homogeneous. We analyzed the patterns of six population parameters: density, biomass, crowding, median individual size, recruitment rate and mortality rate, and four individual traits: growth rate, spawning phenology, maximum size and condition index. Our objectives were (1) to test how intertidal height and orientation of the shore affect individual's traits and population parameters, (2) to infer the link between individual and population level features and (3) to explore the possible upscaling mechanisms driving population structure and processes.

\section{Material and methods}

\subsection{Study site}

The study site, known as Le Petit Minou, is located in the bay of Brest, on the western coast of Brittany, France. Le Petit Minou site constitutes a sheltered macrotidal area, which presents a tidal height range of about $6 \mathrm{~m}$ (ca. $1-7 \mathrm{~m}$ height). It is made of rocky shores on either side of a beach (Fig. 1). The two shores show contrasted mean orientation, the "East shore" orientated toward the West - Southwest and the "West shore" oriented toward the Southeast (Fig. 1). Mussel patches are sparsely distributed on the West rocky shore whereas they form larger and almost continuous patches on the East rocky shore. Mussel patches consisted of only one layer of individuals in the studied area. Although populations of hybrid individuals are found in Brittany region (Bierne et al., 2003), Le Petit Minou site has been characterized by a dominance of Mytilus galloprovincialis (Simon et al., 2020). 
120

121

122

123

124

125

126

127

128

129

130

131

132

133

134

135

136

137

138

139

140

141

142

143

144

145

146

147

148

149

150

151

152

153

154

155

\subsection{Mussel sampling strategy}

Mussel sampling was carried out on the two rocky shores to either side of Le Petit Minou beach, hereafter referred to as the East and West shores. Sampling was performed monthly from March 2019 to February 2020 by sampling three quadrats $(25 \times 25 \mathrm{~cm})$ in each shore. The quadrats were positioned to represent different height positions, i.e., a total of 3 quadrats to represent the entire intertidal height gradient, on each shore (West and East). We sampled areas with at least 20-25\% of mussel cover in low, mean and high height positions along the altitude range of mussel distribution of each shore (about $1.5 \mathrm{~m}$ in the study site). Quadrat location coordinates were recorded using a real-time kinematic (RTK) GPS, with Lambert93 projection. Before sampling, a picture of each quadrat was taken, which was later used to calculate the area of the quadrat covered by mussels by manually delineating the aggregation margins using ImageJ software. A drone survey was performed with a DJI® Phantom 4 pro in June 2019 to assess the topographic heterogeneity. Drone images were taken at a $17-\mathrm{m}$ altitude with an overlap of $80 \%$ between images to optimize the image alignment and produce a relevant digital elevation model (DEM) of the area. We registered multiple reference position points from the mapped area with a RTK GPS to correct for possible distortions in the DEM reconstruction (Jaud et al., 2018). The analysis of drone images and GPS position for the photogrammetric process was performed with Agisoft PhotoScan Pro v1.2.3. Mean aspect, a circular land-surface parameter used to obtain a continuous gradient stressing the north-south or east-west gradient (Olaya, 2009) was calculated in GRASS GIS software. For each shore, aspect was represented as "northness" or "eastness" by deriving the topographic feature orientation (a sine or cosine transformation, respectively) from the DEM (Olaya, 2009). This approach allowed to extract the quadrat samples height position, northness and eastness at the precise coordinates where quadrats were sampled. Height position was referred to the Lowest Astronomical Tide (LAT; the chart datum used for tides predictions and water height measurements).

\subsection{Percentage immersion time}

The mean daily percentage immersion time was determined along the intertidal height gradient in the study site based on the tidal regime measurements over the preceding 5 years (from January 1, 2015 to December 31, 2019) in the study area. Hourly tide gauge measurements of water height at Brest ( $5 \mathrm{~km}$ far from Le Petit Minou) were obtained for the given period from the 'Service hydrographique et océanographique de la Marine' (SHOM; www.data.shom.fr). These measurements were used to fit a cubic polynomial model to compute the mean percentage of immersion time $(\%)$ in relation to intertidal height $(\mathrm{m})$. We then determined the immersion percentage of every sample based on its intertidal height position.

2.4. Sample treatment and primary data

2.4.1. Individual biometric measurements

PeerJ reviewing PDF | (2021:04:60692:2:0:NEW 28 Oct 2021) 
156 All mussels in the quadrat samples were sorted using meshes to select the individuals larger than $1570.05 \mathrm{~cm}$. Individual shell length (SL, $\mathrm{mm}$ ) of all selected individuals was then measured by 158 image analysis, using ImageJ software. Pictures of the individuals larger than ca. $0.5 \mathrm{~cm}$ were 159 taken at $50 \mathrm{~cm}$ height using a canon EOS600D camera, whereas those of small individuals 160 (length < ca. $0.5 \mathrm{~cm}$ ) were performed under a stereo microscope (ZEISS Stemi 508) with a x6.4 161 magnification.

162 For each shore (East and West), thirty individuals were subsampled by selecting ten individuals 163 per quadrat representing its whole range of length ( $>0.5 \mathrm{~cm}$ length), each month for biometric 164 measurements: total wet weight (TWW), flesh wet weight (FWW), flesh dry weight (FDW) and 165 shell length (SL). These individuals were measured using a Vernier caliper and weighed. Their 166 dry mass was then obtained after drying at $60^{\circ} \mathrm{C}$ for $48 \mathrm{~h}$ (until constant weight). Individual

condition index was calculated as $\mathrm{CI}=\mathrm{FDW} / \mathrm{SL}^{3}$ (Petersen et al., 2004).

\subsubsection{Spawning, sex ratio and recruitment}

Histological analyses were performed on 10 individuals above $12 \mathrm{~mm}$ in length of each shore and date. This minimum length corresponds to the reproductive maturity according to Toro, Thompson \& Innes (2002) and van Haren \& Kooijman (1993). Their sex and reproductive stage were determined to characterize the spawning period and sex ratio of the population. The individuals were dissected, and the flesh fixed immediately in Davidson's solution. After 24-48 $\mathrm{h}$, the individuals were transferred to $70 \%$ ethanol, where they were stored until their inclusion in paraffin and histological preparation. The paraffin inclusion process was performed with a Shandon Citadel 2000 Tissue Processor and paraffin blocks were prepared with a cross-section of each individual. The blocks were then sectioned in a microtome to obtain 5- $\mu \mathrm{m}$ layers, which were tinted with hematoxylin and eosin. Pictures of the tissues were taken for further individual reproductive stage determination under an inverted microscope (microscope Leica DMIRB) at x25 magnification. To assess the spawning phenology, we determined the spawning / nonspawning stage following Lubet (1959). Results were presented as the proportion of individuals at the spawning stage and non-spawning stages for each sampling date $(\mathrm{n}=10)$.

Recruitment was evaluated by identifying the individuals with shell length smaller than $1.07 \mathrm{~mm}$ in every sample. These correspond to the length attained at 1 month based on a von Bertalanffy growth function (von Bertalanffy, 1938) calculated from parameters estimated from the site data as a whole (see details in section 2.4.3). Recruitment was represented as the monthly recruit density in a fully covered area, i.e., dividing the number of recruits by the area of the quadrat covered by mussels (estimated from the image of the quadrat).

2.4.3. Individual growth

Individual growth profile was estimated from the seasonally oscillating von Bertalanffy growth function (soVBGF) parameters (Somers, 1988). The individual length distribution of the population, considering all sampled individuals, was used to estimate the parameters of the soVBGF based on length frequency analysis (ELEFAN, Pauly \& David, 1980): 
$194 L_{t}=L_{\text {inf }}\left(1-e^{\left(-K\left(t-t_{0}\right)+S_{t}-S_{t 0}\right)}\right)$

195 where $L_{t}$ is length at age $t, L_{i n f}$ is the asymptotic length, $K$ is the von Bertalanffy growth constant,

$196 t_{0}$ represents the theoretical age when individual length is 0 , and $S_{t}=\frac{C K}{2 \pi} \sin \left(2 \pi\left(t-t_{s}\right)\right)$. $C$ is a 197 constant representing the amplitude of the seasonal growth oscillation, with higher values 198 indicating higher seasonal contrast/oscillation, e.g., $C=0.5$ indicates that growth during the 199 favorable season is increased by $50 \%$ (maximum); $t_{s}$ is a fraction of the year where the sine wave 200 oscillation begins (relative to $t=0$ ), i.e., when it turns positive and shifts towards a season when 201 growth is strongest. In the ELEFAN model, length is related to time rather than age, and the time 202 when length is $0, t_{0}$, can be interpreted as the recruitment time. $t_{0}$ takes values from 0 to 1 , so 0.5 203 means a recruitment period in June. Parameter estimation is based on the shell length mode 204 205 206

207

208

209

210

211

212

213

214 distribution of the population in each shore to account for different distribution shape, in the East and West shores.

The Genetic Algorithm (GA) was applied for the optimization of the fitting process and was implemented with the ELEFAN_GA function from the TropFish package in R software (Taylor and Mildenberger, 2017). The ELEFAN_GA function was applied with a bootstrap approach with 100 resamplings. A first exploration of the best fitting scores of $L_{\text {inf }}$ and $K$ parameter combinations was performed by response surface analysis (RSA) on a wide range of $L_{\text {inf }}(40-140$ $\mathrm{mm})$ and $K(0.01-1)$ values. The range of $L_{\text {inf }}$ searching values of the final analysis was restricted then according to the first exploration. In the parameter estimation analysis, one important factor is the moving average (MA) setting, which can affect parameter estimation since it determines the number of bins used for the moving average (Taylor \& Mildenberger, 2017). A MA of 9 was selected, which corresponds to an approximation of the number of bins spanning the smallest (i.e., youngest) cohort width, as suggested by Taylor \& Mildenberger (2017). This MA selection approach was supported by a sensitivity analysis for evaluation of the results from MA values of

$2183,5,7,9$ and 11.

219 The consistency of $L_{\text {inf }}$ and $K$ parameter results from the ELEFAN_GA approach was validated

220

221

222 by comparing simulated growth curves with a size-age relationship of a set of individuals based on sclerochronology analysis. For the sclerochronology analyses, the shells of individuals of diverse size (17 individuals from the East shore and 17 from the West) were selected and fixed in

223 resin. A longitudinal cut was performed on the resin block and the resulting shell slice was

224 observed under a microscope to count the annual growth marks to estimate individual age. This

225 gave one age-length point from each individual in the validation step.

226 We then compared the growth curves between the West and East shores based on the

227 ELEFAN_GA approach since this analysis considered all sampled individuals. We calculated the

228 overall growth performance phi prime $\left(\varphi^{\prime}\right)$ from the estimated $K$ and $L_{\text {inf }}$ (Munro \& Pauly, 1983)

229 for the West and East shores separately, following the equation:

230

$\varphi^{\prime}=\log _{10}(K)+2 \log _{10}\left(L_{\text {inf }}\right)$ 
232 The age of individuals on the West and East shores was estimated based on their length and the 233 von Bertalanffy growth curve to obtain the age class distribution. From this, the average 234 mortality rate was estimated for each sample as in Blicher, Sejr \& Høgslund (2013), by applying 235 a negative exponential mortality model to the population age distribution:

$236 N_{t}=N_{1} e^{-Z t}$

237 were $N_{l}$ is the number of mussels (ind. $\mathrm{m}^{-2}$ ) in age class $1, N_{t}$ is the number at age $t$, and $Z$ the 238 mortality rate. To avoid bias due to the variability in recruitment density, age class 1 was 239 excluded.

240 2.4.5. Biomass, density, crowding and potential fecundity

241 It is worth mentioning that, in this study, we did not evaluate the covered area as a parameter but 242 we evaluated the structure of the covered area inside the quadrat with diverse population 243 parameters such as biomass, density, crowding, and others derived from biometric traits of 244 individuals (e.g. median shell, see next section). It means these parameters do not represent the 245 real densities or biomass of the entire site but standardized values representing the aggregate 246 composition.

247 The total biomass of each individual was estimated based on the allometric relationship between $248 \mathrm{SL}$ and TWW, TWW $=a \mathrm{SL}^{b}$. Parameters $a$ and $b$ were estimated by a nonlinear least square 249 function approach applied to the ensemble of biometric observations ( $\mathrm{n}$ individuals $=720)(\mathrm{R}$ 250 software, $n l s$ function). Then, total biomass per square meter was obtained from the sum of 251 individual TWW $(\mathrm{kg})$ and the percentage of covered area of each sample, determined from the 252 image of the quadrat:

253 Total biomass $\left(\mathrm{kg} \cdot \mathrm{m}^{-2}\right)=\frac{\sum \mathrm{TWW}}{\mathrm{CC} \mathrm{QA}}$

254

255

256

257

258

259

260

261

262

263

264

265

266

267

268

where TWW is the total mass of each mussel in the quadrat, CC is the "proportion of covered area', i.e., the proportion of the quadrat covered by mussels, and QA is the quadrat area $=0.0625$ $\mathrm{m}^{2}$.

Similarly, density was obtained by dividing the total number of individuals in a quadrat by the mussel-covered area. To examine variations in mussel crowding along the intertidal height gradient, between shores and its relationship with population density and median individual length, a novel "crowding index" was derived. It was defined as the ratio between the observed covered area, corresponding to the visually observed area from the picture analyses (Fig. 2), and the cumulative sum of the basal area of all individuals, derived from the biometric relationship: individual basal area $=\frac{L}{1.8} \frac{L}{2.4}$ (Alunno-Bruscia, Bourget \& Fréchette, 2001), without including recruits. This makes it possible to represent the spatial crowding of individuals inside a patch. A ratio equal to one indicates perfect equivalence between the covered basal area and the observed covered area. Values higher than 1 indicate patches with a high degree of crowding among individuals (Fig. 2A), and values lower than 1 correspond to lower crowding and consequently greater space between individuals (Fig. 2B). Our crowding index quantifies the overlapping 
269

270

271

272

273

274

275

276

277

278

279

280

281

282

283

284

285

286

287

288

289

290

291

292

293

294

295

296

297

298

299

300

301

302

303

304

305

306

degree between individuals of a monolayer aggregation occurring in the study site and is original compared to other approaches (e.g., Guiñez, Castilla \& Sterner, 1999).

Finally, the potential population reproductive output was estimated as the quantity of eggs

released per square meter considering:

- 1:1 sex ratio,

- the mean mussel size distribution on each rocky-shore,

- the contribution of mature individuals (shell length $>12 \mathrm{~mm}$, Van Haren \& Kooijman, 1993; Toro, Thompson \& Innes, 2002),

- a fecundity of $28 \%$ dry mass (van der Veer et al., 2006),

- and the egg quantity - mass equivalence: $10^{6}$ eggs $=52.5 \mathrm{mg}$ (Bayne, Gabbott \& Widdows, 1975).

\subsection{Statistical analysis}

To identify dates where the frequency of spawning individuals differed between the shores, a Gtest of independence was performed between West and East rocky shore areas for each sampling date. A Chi-squared test was performed to test whether the population had a 1:1 sex ratio over the entire study site.

Statistical analyses were performed considering the independent variables: i) West and East shores (i.e., between-shore differences), ii) date (i.e., temporal variation), and iii) intertidal height (in meters, continuous variable). We evaluated the effects of these variables on each population parameter and individual trait (listed in the introduction) by applying general linear models (LM) and a generalized linear model (GLM) in the case of condition index. To fulfil the assumptions of homogeneity of variance and normal distribution of residuals for linear models, a $\log ($ base10) transformation was applied to the density of individuals. The homogeneity of variance of groups was verified using the Levene test with leveneTest function (car package; Fox \& Weisberg, 2019) and visual observation of the residuals versus fitted values. The normal distribution of residuals was verified by their quantile distribution and a Shapiro test of normality using shapiro.test function (stats package; R core team, 2020).

A GLM was performed to test the condition index (CI) using the glm function of the stats package (R Core Team, 2020), with a gamma family and the link function: log, which allows fitting count data with high dispersion. The lsmeans function (lsmeans package; Lenth, 2016) was used to perform all pairwise comparisons using a post-hoc Tukey tests with an adjusted pvalue and alpha of 0.05 .

The spatial variation of the instantaneous mortality rate was tested both along the intertidal height gradient and between the West and East shores, as was the interaction between these factors. This was performed by applying a general linear mixed model (LMM) with $\log 10$ transformed response variable and sampling date as a random factor using the lmer function (lme4 package; Bates et al., 2015). The effect of adult density on the recruit density was also tested in addition to the effect of shore, date and intertidal height. One LM was done with all 
307 these independent variables and a second with the significant factors, adult density and date to 308 identify the months with significant differences.

309 Finally, the significance of the relationships between crowding index and the population

310 parameters density, median individual length and shore (East/West), were analyzed using a

311 LMM. Density of individuals and median individual length were considered as fixed factors and

312 date as a random factor. The assumption of the normal distribution of residuals were verified

313 with a Shapiro-Wilk normality test. For this analysis, density and median length of population

314 size distribution were calculated without including recruits because the latter do not contribute

315 greatly to crowding.

\section{3. Results}

317 3.1. Intertidal height range and immersion percentage of mussel samples

318 The samples covered the entire intertidal height gradient on both West and East shores, ranging

319 from 3.55 to $5.09 \mathrm{~m}$, corresponding to a yearly-averaged immersion time varying from 34.47 to

$32061.16 \%$ (Fig. 3). The West shore showed mussel patches along almost the whole of this intertidal

321 height range, whereas the East shore reached the lower limit of mussel distribution at a higher

322 intertidal height $(4 \mathrm{~m})$. The orientation of samples on the two shores presented significant

323 differences in eastness and northness features. The samples from the West shore were mainly

324 orientated toward the south and almost perpendicular to the east, whereas the East shore samples

325 were oriented to the west and almost perpendicular to the north-south axis (Figure S1).

326

327

328

329

330

331

332

333

334

335

336

337

338

339

340

341

342

343

344

\subsection{Condition index, spawning, sex ratio and recruitment}

The sex ratio was not significantly different from 1:1 according to a Chi-squared test. The condition index (CI) was only significantly higher on the West shore than on the East shore in August, and there were some significant differences between dates depending on shore (Table 1, Table S1, Fig. 4 A). CI was significantly lower during March-April 2019 and February 2020 on the West shore, and during March 2019 and February 2020 on the East shore, compared with the period June-September 2019 (Fig. 4 A, Table S1). Furthermore, CI was not significantly related to the intertidal height (Table 1, Table S2). The temporal variation of CI was consistent with the variation in reproductive stage of individuals, with significantly lower CI during the spawning periods (Fig. 4, Table S2). The proportion of individuals at the spawning stage varied through the year with two main periods of increase during March-May and September-November, with some differences between the West and East shores during the second period (Fig. 4 B).

Differences between the shores were revealed by G-tests in which there was nonindependence of the frequencies of spawning individuals in July $(G=4.69$, $p$-value $=0.03)$, November $(G=5.3$, $\mathrm{p}$-value $=0.02)$ and February $(\mathrm{G}=4.07$, p-value $=0.04)$.

Recruit density indicated an almost continuous recruitment, with significant differences between dates and the same temporal pattern on both shores (Table 1, Fig. 4 C). Recruit density also had a nonsignificant relationship with intertidal height, but a significant positive relationship with the density of adult individuals at both shores considered. The relationship with adult density was 
345 non-significantly different between shores, i.e., non-significant interaction (Table 1, Table S2, 346 Fig. 5). The highest recruitment occurred from April to September, with a significantly higher

347 density in August relative to most other months. Secondary increases were also seen on the West 348 shore in December 2019 and February 2020, although they were not statistically significant (Fig. $3494 \mathrm{C}$ ). The first recruitment periods followed the increase of the proportion of individuals at the 350 spawning stage (March-May 2019), but the higher recruit density was observed 3 months after 351 the end of this period (August). The second increase in the proportion of individuals in spawning 352 stage, September-November 2019, was followed by a small (non-significant) increase in recruit 353 density in December, in the west shore (Fig. 4).

354

355

356

357

358

359

360

361

362

363

364

365

366

367

368

369

370

371

372

373

374

375

376

377

378

379

380

381

382

383

\subsection{Individual Growth}

The soVBGF parameters indicate differences between the two shores, with $K=0.12, L_{\text {inf }}=$ 65.25, $C=0.42, t_{s}=0.56$ and $\varphi=2.71$ in the West, and $K=0.19, L_{\text {inf }}=62.54, C=0.51, t_{s}=0.5$ and $\varphi=2.87$ in the East (Fig. 6). Both curves are shown in Figure 6, with the estimated parameters and $\mathrm{t}_{0}$ equal to 0.52 and 0.67 for the West and East, respectively. Moreover, these estimated growth curves matched with the range of the age-at-length data derived from the sclerochronology analysis (Fig. 6).

\subsection{Mortality}

The instantaneous mortality rate $(Z)$ varied from 0.43 to $1.43 \mathrm{yr}^{-1}$, with a mean of $0.642( \pm 0.170$ $\mathrm{SD})$ in the West and $0.919( \pm 0.246 \mathrm{SD})$ in the East. The result from the LMM indicated that the log-transformed mortality rate $(Z)$ was significantly different between the two shores and was positively related to the intertidal height in both, i.e., mortality increases as intertidal height increases (Fig. 7, Table 2, Table S2).

\subsection{Population biomass, size structure, density and crowding}

No significant difference in total biomass was found between the East and West shores or between sampling dates (Table 1, Table S2). There was a significant interaction indicating a shore-dependent intertidal height effect on biomass, but this was due to two very influential points in the highest topographic position in the entire site. As these points were outside the common range of distribution between West and East, we did not consider them in the final analysis, so there was no significant intertidal height effect on the biomass (Table 1, Table S2, Fig. 8 A).

A significantly higher density of individuals was found on the West shore than on the East, without any differences between dates (Table 1, Table S2, Fig. 8 B). In addition, there was a significant intertidal height effect on the density of individuals, with the same positive trend in both rocky-shores (Table 1, Table S2-S3, Fig. 8 B).

The median length of individuals was significantly higher on the East shore than on the West and was significantly positively related to the intertidal height position on both shores (Table 1, Table S2-S3, Fig. 8 C). There was a significant higher maximum length in the East than in the 
384 West with no differences between dates. Maximal length was significantly negatively related to

385

386

387

388

389

390

391

392

393

394

395

396

397

398

399

400

401

402

403

404

405

406

407

408

409

410

411

412

413

414

415

416

417

418

419

420

421

422

intertidal height (Table 1, Table S2-S3, Fig. 8 D).

There were no significant differences in the crowding index either between West and East or between dates (LM results, Table 1, Fig. 8 E). Crowding index was positively related to the density of adult individuals and the median length of adult individuals of the population, with a lower slope in the first case (LMM results, Table 1, Table S2-S3, Fig. 8 F).

\subsection{Individual and population fecundity}

Considering the mean size distribution of the population on each shore, the potential reproductive output was very similar between the two shores: $112.92( \pm 42, \mathrm{SD})$ and $106.5( \pm 32$, SD) g. $\mathrm{m}^{-2}$ in West and East, respectively (Fig. 9). This was equivalent to a total of $2.15 \times 10^{9}$ and $2.03 \times 10^{9}$ eggs. $\mathrm{m}^{-2}$ released per covered square meter in the West and East, respectively (Fig. 9). The mean total density of reproductively mature individuals (individuals of size $>12 \mathrm{~mm}$, Toro, Thompson \& Innes, 2002) were 8819 and 7939 ind. $\mathrm{m}^{-2}$ in the West and East, respectively.

\section{Discussion}

By combining spatial and temporal observations, we uncovered several patterns related to the phenology of spawning and recruitment, population dynamics and aggregation structure of mussels on two rocky shores. Our results revealed asynchrony between spawning and recruitment, two life history traits of fundamental importance for population persistence. We observed that the spatial variability in spawning phenology allowed a second spawning during higher stress summer conditions. Additionally, our results showed that individual and population patterns contrasted with biomass stability along the intertidal height and between the two rocky shores. In the following paragraphs, we discuss these results and the possible mechanisms underlying the aggregation structure by examining the relationships among the observed patterns of density, size distribution, growth, mortality and recruitment.

\subsection{Phenology of spawning and recruitment}

Spawning and recruitment phenology determine the conditions to which larvae and recruits are exposed and will, consequently, affect population dynamics. Recruitment occurs after the spawning period, larvae development and settlement. Larvae may recruit in the same area as their progenitors, i.e., self-recruitment, presumably 2-3 weeks after the progenitors spawned. However, larvae can also disperse and settle in other areas and, in this case, the lack of selfrecruitment can be observed as local asynchrony between spawning and recruitment dynamics. Other causes of asynchrony are recruitment failure or a primary recruitment on other sites than the mussel bed, as in filamentous algae (Bayne, 1964). Temperature and feeding conditions determine individual spawning and recruitment phenology and success along the coast. In general, there is one main spawning period at high latitudes (e.g., Kautsky, 1982; Antsulevich, Maximovich \& Vuorinen, 1999; Thorarinsdóttir \& Gunnarsson, 2003) and two periods in temperate regions (e.g., Seed, 1976; Lowe, Moore \& Bayne, 1982). In our study site, spawning, although continuous, peaked in spring and autumn in agreement with prior observations in the 
423 Brittany region (Lubet, 1959; Lacroix et al., 2017). Similarly, recruitment was also continuous 424 and generally low, with peaks in spring and summer. Thus, we observed synchrony between 425 recruitment and spawning dynamics during spring and asynchrony during summer and autumn.

426 During summer, the asynchrony, which was caused by a peak of recruitment without a preceding 427 peak of spawning, could have resulted from the arrival of larvae from other sites with differing 428 reproductive phenology. In autumn, the asynchrony, which involved a peak in spawning without 429 a following peak in recruitment, may be related to the dispersion of larvae to other sites, 430 recruitment failure or recruitment on other substrates not analyzed in this study. These 431 asynchronies between recruitment and spawning highlight the influence of larval dispersion and 432 connectivity in the population dynamics of the study site. Thomas et al. (2020) pointed out the 433 fundamental role of connectivity between sites for population dynamics along the coast of this 434 region. Thus, the studied population at this site may have a dynamic, undefined role in overall 435 population connectivity, i.e., acting as a larval supplier or receiver, depending on the season and 436 environmental conditions.

437 Variation in spawning phenology within the study site was also observed, suggesting different 438 temporal dynamics of microclimate conditions between the two shores. Microclimate conditions 439 may change due to the interactions between factors such as wind speed, wave height, solar radiation, time of low tide and angle of substrate (Denny, Miller \& Harley, 2006; Seabra et al., 2011; Helmuth et al., 2011; Choi et al., 2019). These factors can be particularly contrasted

443

444

445

446

447

448

449

450

451

452

453

454

455

456

457

458

459

460

461

462 between West and East shores due to their different orientation. Consequently, individuals showed temporal variations in performance between shores. For instance, both a lack of spawning during July and lower condition index during August suggest a decrease in the performance of individuals on the East shore during summer compared with the West. Summer conditions were characterized by a high maximum aerial temperature (maxima of $27^{\circ} \mathrm{C}$ and $25^{\circ} \mathrm{C}$ in July and August, respectively, https://www.historique-

meteo.net/france/bretagne/brest/2019/07/), high SST (almost $3^{\circ} \mathrm{C}$ higher than the mean of the last nine years, data not shown) and low tide periods at midday. Choi et al. (2019) estimated that higher variation in substrate temperature (ranging from $25.7^{\circ} \mathrm{C}$ to $41.4^{\circ} \mathrm{C}$ ) could be due to cooccurring high aerial temperature and high solar radiation, which is likely what took place in our study site. Gametogenesis can be slowed by high temperatures of water (Fearman \& Moltschaniwskyj, 2010) and seawater temperatures higher than $20^{\circ} \mathrm{C}$ can accelerate gamete release (Múgica et al., 2015), which may explain the observed discontinuity of spawning between month, and presence of oocyte atresia (data not shown). Also, a low condition index, i.e., loss of individual weight, which is mainly related either to spawning or physiological stress periods, was observed during August (when no spawning occurred) suggesting physiological stress.

Based on these observations, we hypothesize that the observed shore differences in the reproductive stage and condition of individuals were related to a temporal change in the microclimate, specifically the high temperatures recorded. The temperature also drives the reproductive phenology at within-site scale. Our work suggests the likely role of the different 
463 shore orientations within the studied site. That is, the different shore orientations potentially 464 create refuges during stressful conditions. The different microclimates between shores were 465 fundamental during summer because they allowed a second spawning period on the West shore, 466 where in general conditions individuals grow slower. This is an example of how, during 467 fluctuating conditions, individuals living in suboptimal conditions can show a higher 468 performance than individuals living in more optimal conditions, i.e., the "suboptimal can be 469 optimal" (Martin \& Huey, 2008), which ensures their contribution to the gametes that will make 470 the future cohort.

471

472

473

474

475

476

477

478

479

480

481

482

483

484

485

486

487

488

489

490

491

492

493

494

495

496

497

498

499

500

501

502

\subsection{Variability of traits contrasts with stability of biomass}

Unexpectedly, biomass was stable in both space and time in our study. This pattern of biomass stability results from the interaction between the patterns of individual traits and population parameters and is mediated by a relatively constant crowding of individuals. The aggregation structure itself results from a trade-off between the density and size of individuals. More individuals can occupy a given area if they are smaller. This pattern has already been observed in single-layer mussel aggregations (Petraitis, 1995). Population size structure and density are affected by both individual- and population-level processes, such as growth, recruitment and mortality. Petraitis (1995) pointed out that these processes can drive the capacity of a mussel bed to keep the covered area constant. Keeping the covered area constant is also associated with keeping the crowding constant to maintain the aggregation structure of a $100 \%$ covered area. The aggregation structure can remain constant if individual mussels move and tend to segregate, which has been observed in sandy environments (Liu et al., 2014) and may play a fundamental role in the aggregation pattern observed on rocky shores. Nevertheless, movement behavior under stressful wave conditions can increase the probability of dislodgement/mortality, as suggested in a M. edulis population by Schneider et al. (2005). We hypothesize, therefore, that growth, mortality and recruitment rates can also play a role in the stability of the crowding structure of an aggregation. This is supported by the observed patterns of individual growth rate, mortality and recruitment throughout the site, between shores and along the intertidal height gradient. The higher individual growth rate observed on the East shore could compensate for the higher loss of covered area or decrease of crowding due to mortality, forming mussel

aggregations of larger individuals with a lower density, as observed. Conversely, on the West shore, vacant space can be filled due to higher recruitment, despite lower growth rates forming highly dense aggregations of small individuals. A similar pattern emerged along the intertidal height gradient. The higher mortality observed at increasing intertidal height could be compensated by the higher recruitment, but not likely by the growth rate since individuals grow slower at high intertidal height due to lower proportion of time in immersion. The densitydependent recruitment process observed is fundamental for maintaining the crowding level, particularly under lower growth rate conditions. This is because, when growth is slow, several individuals will fill a determined gap caused by mortality of an individual much faster than a few individuals growing slowly. Density-dependent recruitment has already been observed in other studies (e.g., McGrorty, Goss-Custard \& Clarke, 1993; Dolmer \& Stenalt, 2010). 
503 For sessile species on rocky-shores, space is a limiting factor, and the dynamics of space 504 availability are fundamental for understanding population and community dynamics. The 505 crowding structure of the population in our study indicated a highly compacted positioning of 506 individuals. The sum of the basal area of individuals was as much as $50 \%$ higher than the 507 observed covered area (crowding of 1.5), which indicates that the general hypothesis that the 508 sum of area occupied by the sum of individuals is equal to the covered area (crowding equal to 1) 509 is not corroborated in wild populations. This assumption was considered for modeling the space 510 occupation in monolayer mussel beds (e.g., Roughgarden, Iwasa \& Baxter, 1985; Petraitis, 511 1995), and its violation could mean an overestimation of the occupied area and consequently the 512 possible limitation of available space for expansion of a population. Furthermore, the 513 aggregation structure is important for patch stability and population persistence (Dugatkin, 514 Mesterton-Gibbonsand \& Houston, 1992; Guichard et al., 2003; Liu et al., 2014; Guichard,

515

516

517

518

519

520

521

522

523

524

525

526

527

528

529

530

531

532

533

534

535

536

537

538

539

540

541

2017). For instance, in our study site, the aggregation structure may increase patch stability, as indicated by the longevity of some individuals, found to be around 11 years old, which may underpin the persistence of this population. Thus, representing the mechanisms underlying the spatial occupation and crowding structure of mussel aggregations in rocky environments could allow an exploration of the population response under changing conditions (e.g., Zardi et al., 2021).

Interestingly, despite the different population size distribution between the two shores, our estimates indicate similar potential reproductive output (eggs per square meter), suggesting a density-size trade-off. This is to say that high-density patches of small mussels may have a similar egg production as sparser patches of large mussels, under the assumption of similar individual reproductive output (but see Sukhotin et al., 2009) and 1:1 sex ratio observed in the study site. Thus, we hypothesize that the structure of the patches would tend to maintain or carry a maximum of biomass due to trade-offs between density and size while maintaining and maximizing the reproductive output.

\subsection{Environmental heterogeneity underlying individual traits and population parameters} patterns

The patterns of spatial variability of individual traits and population parameters in our study site suggest that heterogeneous environmental conditions influence variation in individual- and population-level processes. In our site, shore orientation likely determined different temperatures (e.g., Helmuth, 1998; Choi et al., 2019), whereas intertidal height gradient determine the duration of emersion. During emersion time, orientation heterogeneity and intertidal height could determine the maximum temperature and the duration of exposition to such temperature, respectively. Combining the temperature and duration of exposure is fundamental in regulating the mortality by heat stress (Harley, 2008; Mislan and Wethey, 2015; Seuront et al., 2019). This could be linked to the observed patterns of increasing mortality when increasing intertidal height due to a higher time of exposure. In addition, energetic demand depends on temperature, which could explain the observed differences on growth rate. 
542 Nevertheless, determining the main driver of the observed patterns could be difficult due to the 543 combination of multiple environmental factors. For instance, topographic orientation combined

544 with slope can increase the wave exposition and intensity (Guichard, Bourge \& Robert, 2001;

545 Denny et al., 2004), causing higher mortality by dislodgement (McQuaid and Lindsay, 2000) and

546 determine the swash and potential differences in immersion/emersion time. Furthermore,

547 individuals exposed to similar thermal stress conditions (same temperature and duration) show

548 higher survival if they have more food available, i.e., more energy to support the stress

549 (Fitzgerald-Dehoog et al., 2012). This reinforces our interpretation of the gradients observed

550 along the intertidal height gradient. Individuals located at low height, with longer immersion

551 times, have greater access to food and consequently lower mortality rates.

\section{Conclusions}

553 This study constitutes an integrative characterization of a wild rocky-shore mussel population at

554 both spatial and temporal scales, and at individual to population level. This integrative analysis

555 allowed us to evaluate the patterns and relationships between the main individual traits and

556 population parameters. Moreover, our results shed light on how the interaction of processes at

557 the individual scale could drive the patterns observed at population scale. The next steps needed

558 to gain insight into the system dynamics should address the environmental drivers underlying the

559 variability of processes creating the observed patterns. Analysis of current aerial images to

560 represent and characterize the terrain surface, and to assess the target species distribution (e.g.,

561 Gomes et al., 2018) may be a suitable approach for identifying the environmental changes at

562 desired scales (microclimates) (e.g., Choi et al., 2019; Kearney et al., 2020). Finally, linking all

563 the information together, including the patterns, processes and environmental variability, in

564 mechanistic models may be a promising avenue for testing the hypothesis that emerged here,

565 such as the local effect of temperature on the phenology of reproduction, and the mechanisms of

566 crowding and its role in population resistance to stress and disturbances.

\section{Acknowledgements}

568 We thank Eric Dabas for processing the sclerochronology samples and Nelly Le Goic for advice on 569 histological analyses. We thank Jérôme Ammann, Amicie d'Augustin, Even Tangui, Elodie

570 Bessis, Mariana Ventura, Anaïs Medieu, Jordan Toullec, Joan M. Alfaro-Lucas and Yann

571 Kearjean for their help in the field. We thank Helen McCombie for English editing and valuable

572 comments, and the three anonymous reviewers for their comments, which helped us to improve

573 our manuscript.

574

\section{References}

576 Alunno-Bruscia M, Bourget E, Fréchette M. 2001. Shell allometry and length-mass-density

577 relationship for Mytilus edulis in an experimental food-regulated situation. Marine Ecology

578 Progress Series 219:177-188. DOI: 10.3354/meps219177. 
579 Antsulevich AE, Maximovich NV, Vuorinen I. 1999. Population structure, growth and 580 reproduction of the common mussel (Mytilus edulis L.) off the Island of Seili (SW Finland). 581 Boreal Environment Research 4:367-375.

582 Arribas LP, Donnarumma L, Palomo MG, Scrosati RA. 2014. Intertidal mussels as ecosystem 583 engineers: their associated invertebrate biodiversity under contrasting wave exposures. Marine 584 Biodiversity 44:203-211. DOI: 10.1007/s12526-014-0201-z.

585 Bates D, Mächler M, Bolker B, Walker S. 2015. Fitting Linear Mixed-Effects Models Using 586 Ime4. Journal of Statistical Software 67:1-48. DOI: 10.18637/jss.v067.i01.

587 Bayne BL. 1964. Primary and Secondary Settlement in Mytilus edulis L. (Mollusca). Journal of 588 Animal Ecology 33:513-523. DOI: 10.2307/2569.

589 Bayne BL, Gabbott PA, Widdows J. 1975. Some effects of stress in the adult on the eggs and 590 larvae of Mytilus edulis L. Journal of the Marine Biological Association of the United Kingdom 591 55:675-689. DOI: 10.1017/S0025315400017343.

592 von Bertalanffy L. 1938. A quantitative theory of organic growth (inquiries on growth laws. II). 593 Human Biology 10(2): 181-213.

594 Bertness MD, Grosholz E. 1985. Population dynamics of the ribbed mussel, Geukensia demissa: 595 The costs and benefits of an aggregated distribution. Oecologia 67:192-204. DOI:

$59610.1007 / \mathrm{BF} 00384283$.

597 Bertolini C, Montgomery WI, O'Connor NE. 2018. Habitat with small inter-structural spaces 598 promotes mussel survival and reef generation. Marine Biology 165:163. DOI: 10.1007/s00227599 018-3426-8.

600 Bierne N, Borsa P, Daguin C, Jollivet D, Viard F, Bonhomme F, David P. 2003. Introgression 601 patterns in the mosaic hybrid zone between Mytilus edulis and M. galloprovincialis. Molecular 602 Ecology 12:447-461. DOI: 10.1046/j.1365-294X.2003.01730.x.

603 Blanchette CA, Broitman BR, Gaines SD. 2006. Intertidal community structure and 604 oceanographic patterns around Santa Cruz Island, CA, USA. Marine Biology 149:689-701. DOI: 605 10.1007/s00227-005-0239-3.

606 Blanchette CA, Gaines SD. 2007. Distribution, abundance, size and recruitment of the mussel, 607 Mytilus californianus, across a major oceanographic and biogeographic boundary at Point 608 Conception, California, USA. Journal of Experimental Marine Biology and Ecology 340:268609 279. DOI: 10.1016/j.jembe.2006.09.014.

610 Blanchette CA, Helmuth B, Gaines SD. 2007. Spatial patterns of growth in the mussel, Mytilus 611 californianus, across a major oceanographic and biogeographic boundary at Point Conception, 612 California, USA. Journal of Experimental Marine Biology and Ecology 340:126-148. DOI:

613 10.1016/j.jembe.2006.09.022. 
614 Blicher M, Sejr M, Høgslund S. 2013. Population structure of Mytilus edulis in the intertidal 615 zone in a sub-Arctic fjord, SW Greenland. Marine Ecology Progress Series 487:89-100. DOI: $61610.3354 /$ meps 10317.

617 Borthagaray AI, Carranza A. 2007. Mussels as ecosystem engineers: Their contribution to 618 species richness in a rocky littoral community. Acta Oecologica 31:243-250. DOI:

619 10.1016/j.actao.2006.10.008.

620 Choi F, Gouhier T, Lima F, Rilov G, Seabra R, Helmuth B. 2019. Mapping physiology:

621 biophysical mechanisms define scales of climate change impacts. Conservation Physiology

622 7:coz028. DOI: 10.1093/conphys/coz028.

623 Commito JA, Rusignuolo BR. 2000. Structural complexity in mussel beds: the fractal geometry 624 of surface topography. Journal of Experimental Marine Biology and Ecology 255:133-152. DOI: 625 10.1016/S0022-0981(00)00285-9.

626 Denny MW. 1987. Lift as a mechanism of patch initiation in mussel beds. Journal of

627 Experimental Marine Biology and Ecology 113:231-245. DOI: 10.1016/0022-0981(87)90103-1.

628 Denny MW, Dowd WW, Bilir L, Mach KJ. 2011. Spreading the risk: Small-scale body

629 temperature variation among intertidal organisms and its implications for species persistence.

630 Journal of Experimental Marine Biology and Ecology 400:175-190. DOI:

631 10.1016/j.jembe.2011.02.006.

632 Denny MW, Helmuth B, Leonard GH, Harley CDG, Hunt LJH, Nelson EK. 2004. Quantifying 633 scale in ecology: lessons from awave-swept shore. Ecological Monographs 74:513-532. DOI:

$63410.1890 / 03-4043$.

635 Denny MW, Miller LP, Harley CDG. 2006. Thermal stress on intertidal limpets: long-term 636 hindcasts and lethal limits. Journal of Experimental Biology 209:2420-2431. DOI:

$63710.1242 / \mathrm{jeb} .02258$.

638 Dolmer P, Stenalt E. 2010. The impact of the adult blue mussel (Mytilus edulis) population on 639 settling of conspecific larvae. Aquaculture International 18:3-17. DOI: 10.1007/s10499-009640 9266-2.

641 Dong Y, Li X, Choi FMP, Williams GA, Somero GN, Helmuth B. 2017. Untangling the roles of 642 microclimate, behaviour and physiological polymorphism in governing vulnerability of intertidal 643 snails to heat stress. Proceedings of the Royal Society B: Biological Sciences 284:20162367.

644 DOI: $10.1098 / \mathrm{rspb} .2016 .2367$.

645 Dugatkin LA, Mesterton-Gibbonsand M, Houston AI. 1992. Beyond the prisoner's dilemma: 646 Toward models to discriminate among mechanisms of cooperation in nature. Trends in Ecology 647 \& Evolution 7:202-205. DOI: 10.1016/0169-5347(92)90074-L. 
648 Fearman J, Moltschaniwskyj NA. 2010. Warmer temperatures reduce rates of gametogenesis in 649 temperate mussels, Mytilus galloprovincialis. Aquaculture 305:20-25. DOI:

650 10.1016/j.aquaculture.2010.04.003.

651 Fitzgerald-Dehoog L, Browning J, Allen BJ. 2012. Food and Heat Stress in the California 652 Mussel: Evidence for an Energetic Trade-off Between Survival and Growth. The Biological 653 Bulletin 223:205-216. DOI: 10.1086/BBLv223n2p205.

654 Fox J, Weisberg S (2019). An R Companion to Applied Regression, Third edition. Sage, 655 Thousand Oaks CA. https://socialsciences.mcmaster.ca/jfox/Books/Companion/.

656 Gomes I, Peteiro L, Bueno-Pardo J, Albuquerque R, Pérez-Jorge S, Oliveira ER, Alves FL, 657 Queiroga H. 2018. What's a picture really worth? On the use of drone aerial imagery to estimate 658 intertidal rocky shore mussel demographic parameters. Estuarine, Coastal and Shelf Science 659 213:185-198. DOI: 10.1016/j.ecss.2018.08.020.

660 Grimm V, Revilla E, Berger U, Jeltsch F, Mooij WM, Railsback SF, Thulke H-H, Weiner J, 661 Wiegand T, DeAngelis DL. 2005. Pattern-Oriented Modeling of Agent-Based Complex Systems: 662 Lessons from Ecology. Science 310:987-991. DOI: 10.1126/science.1116681.

663 Guichard F. 2017. Regular patterns link individual behavior to population persistence.

664 Proceedings of the National Academy of Sciences 114:7747-7749. DOI:

665 10.1073/pnas.1709063114.

666 Guichard F, Bourget E, Robert J. 2001. Scaling the influence of topographic heterogeneity on 667 intertidal benthic communities: alternate trajectories mediated by hydrodynamics and shading. 668 Marine Ecology Progress Series 217:27-41. DOI: 10.3354/meps217027.

669 Guichard F, Halpin PM, Allison GW, Lubchenco J, Menge BA. 2003. Mussel Disturbance 670 Dynamics: Signatures of Oceanographic Forcing from Local Interactions. The American 671 Naturalist 161:889-904. DOI: 10.1086/375300.

672 Guiñez R, Castilla JC, Sterner AERW. 1999. A Tridimensional Self-Thinning Model for 673 Multilayered Intertidal Mussels. The American Naturalist 154:341-357. DOI: 10.1086/303234.

674 Gutiérrez J, Palomo M, Bagur M, Arribas L, Soria S. 2015. Wave action limits crowding in an 675 intertidal mussel. Marine Ecology Progress Series 518:153-163. DOI: 10.3354/meps 11086.

676 Harley C. 2008. Tidal dynamics, topographic orientation, and temperature-mediated mass 677 mortalities on rocky shores. Marine Ecology Progress Series 371:37-46. DOI:

$678 \quad 10.3354 /$ meps 07711.

679 Helmuth BST. 1998. Intertidal Mussel Microclimates: Predicting the Body Temperature of a 680 Sessile Invertebrate. Ecological Monographs 68:51-74. DOI: https://doi.org/10.1890/0012681 9615(1998)068[0051:IMMPTB]2.0.CO;2.

682 Helmuth B, Broitman BR, Blanchette CA, Gilman S, Halpin P, Harley CDG, O'Donnell MJ, 683 Hofmann GE, Menge B, Strickland D. 2006. Mosaic Patterns of Thermal Stress in the Rocky 
684 Intertidal Zone: Implications for Climate Change. Ecological Monographs 76:461-479. DOI:

685 https://doi.org/10.1890/0012-9615(2006)076[0461:MPOTSI]2.0.CO;2.

686 Helmuth B, Yamane L, Lalwani S, Matzelle A, Tockstein A, Gao N. 2011. Hidden signals of 687 climate change in intertidal ecosystems: What (not) to expect when you are expecting. Journal of 688 Experimental Marine Biology and Ecology 400:191-199. DOI: 10.1016/j.jembe.2011.02.004.de 689 Jager M, van de Koppel J, Weerman EJ, Weissing FJ. 2020. Patterning in Mussel Beds 690 Explained by the Interplay of Multi-Level Selection and Spatial Self-Organization. Frontiers in 691 Ecology and Evolution 8:7. DOI: 10.3389/fevo.2020.00007.

692 de Jager M, Weissing FJ, Herman PMJ, Nolet BA, van de Koppel J. 2011. Levy Walks Evolve 693 Through Interaction Between Movement and Environmental Complexity. Science 332:1551694 1553. DOI: $10.1126 /$ science. 1201187.

695 Jaud M, Passot S, Allemand P, Le Dantec N, Grandjean P, Delacourt C. 2018. Suggestions to 696 Limit Geometric Distortions in the Reconstruction of Linear Coastal Landforms by SfM 697 Photogrammetry with PhotoScan $\AA$ and MicMac $®$ for UAV Surveys with Restricted GCPs 698 Pattern. Drones 3:2. DOI: 10.3390/drones3010002.

699 Kautsky N. 1982. Quantitative studies on gonad cycle, fecundity, reproductive output and 700 recruitment in a baltic Mytilus edulis population. Marine Biology 68:143-160. DOI:

701 10.1007/BF00397601.

702 Kearney MR, Gillingham PK, Bramer I, Duffy JP, Maclean IMD. 2020. A method for computing 703 hourly, historical, terrain-corrected microclimate anywhere on earth. Methods in Ecology and 704 Evolution 11:38-43. DOI: https://doi.org/10.1111/2041-210X.13330.

705 van de Koppel J, Gascoigne JC, Theraulaz G, Rietkerk M, Mooij WM, Herman PMJ. 2008. 706 Experimental Evidence for Spatial Self-Organization and Its Emergent Effects in Mussel Bed 707 Ecosystems. Science 322:739. DOI: 10.1126/science.1163952.

708 Lacroix C, Duvieilbourg E, Guillou N, Guyomarch J, Bassoulet C, Moraga D, Chapalain G, 709 Auffret M. 2017. Seasonal monitoring of blue mussel (Mytilus spp.) populations in a harbor area:

710 A focus on responses to environmental factors and chronic contamination. Marine

711 Environmental Research 129:24-35. DOI: 10.1016/j.marenvres.2017.04.008.

712 Lenth RV, 2016. Least-Squares Means: The R Package lsmeans. Journal of Statistical Software 713 69(1): 1-33. doi:10.18637/jss.v069.i01

714 Liu Q-X, Herman PMJ, Mooij WM, Huisman J, Scheffer M, Olff H, van de Koppel J. 2014.

715 Pattern formation at multiple spatial scales drives the resilience of mussel bed ecosystems.

716 Nature Communications 5:5234. DOI: 10.1038/ncomms6234.

717 Lowe DM, Moore MN, Bayne BL. 1982. Aspects of Gametogenesis in the Marine Mussel

718 Mytilus Edulis L. Journal of the Marine Biological Association of the United Kingdom 62:133-

719 145. DOI: $10.1017 /$ S0025315400020166. 
720 Lubet P. 1959. Recherches sur le cycle sexuel et l'émission des gamètes chez les mytilides et les 721 pectinides (Mollusques bivalves). Revue des travaux de l'Institut des pêches maritimes 23:164.

722 Martin TL, Huey RB. 2008. Why "Suboptimal” Is Optimal: Jensen's Inequality and Ectotherm

723 Thermal Preferences. The American Naturalist 171:E102-E118. DOI: 10.1086/527502.

724 McGrorty S, Goss-Custard JD, Clarke RT. 1993. Mussel Mytilus edulis (Mytilacea) dynamics in 725 relation to environmental gradients and intraspecific interactions. Netherland Journal of Aquatic 726 Ecology 27:163-171. DOI: 10.1007/BF02334779.

727 McQuaid C, Lindsay T. 2000. Effect of wave exposure on growth and mortality rates of the 728 mussel Perna perna: bottom-up regulation of intertidal populations. Marine Ecology Progress 729 Series 206:147-154. DOI: 10.3354/meps206147.

730 Menge BA. 1976. Organization of the New England Rocky Intertidal Community: Role of

731 Predation, Competition, and Environmental Heterogeneity. Ecological Monographs 46:355-393. 732 DOI: $10.2307 / 1942563$.

733 Miller LP, Dowd WW. 2019. Repeatable patterns of small-scale spatial variation in intertidal 734 mussel beds and their implications for responses to climate change. Comparative Biochemistry 735 and Physiology Part A: Molecular \& Integrative Physiology 236:110516. DOI:

736 10.1016/j.cbpa.2019.06.016.

737 Mislan K a. S, Wethey DS. 2015. A biophysical basis for patchy mortality during heat waves. 738 Ecology 96:902-907. DOI: https://doi.org/10.1890/14-1219.1.

739 Múgica M, Sokolova IM, Izagirre U, Marigómez I. 2015. Season-dependent effects of elevated 740 temperature on stress biomarkers, energy metabolism and gamete development in mussels.

741 Marine Environmental Research 103:1-10. DOI: 10.1016/j.marenvres.2014.10.005.

742 Munro JL, \& Pauly D. 1983. A simple method for comparing the growth of fishes and 743 invertebrates. Fishbyte 1(1): 5-6.

744 Paine RT. 1971. A Short-Term Experimental Investigation of Resource Partitioning in a New

745 Zealand Rocky Intertidal Habitat. Ecology 52:1096-1106. DOI: https://doi.org/10.2307/1933819.

746 Paine RT. 1974. Intertidal community structure. Oecologia 15:93-120. DOI:

$747 \quad 10.1007 / \mathrm{BF} 00345739$.

748 Pauly D, David N. 1980. An objective method for determining fish growth from length-

749 frequency data. ICLARM Newsletter 3(3): 13-15.

750 Petersen J, Bougrier S, Smaal A, Garen P, Robert S, Larsen J, Brummelhuis E. 2004.

751 Intercalibration of mussel Mytilus edulis clearance rate measurements. Marine Ecology Progress

752 Series 267:187-194. DOI: 10.3354/meps267187.

753 Petraitis PS. 1995. The Role of Growth in Maintaining Spatial Dominance by Mussels (Mytilus 754 edulis). Ecology 76:1337-1346. DOI: https://doi.org/10.2307/1940940. 
755 R Core Team, 2020. R: A language and environment for statistical computing. R Foundation for 756 Statistical Computing, Vienna, Austria. URL https://www.R-project.org/.

757 Roughgarden J, Iwasa Y, Baxter C. 1985. Demographic theory for an open marine population 758 with space- limited recruitment. Ecology 66:54-67. DOI: 10.2307/1941306.

759 Schneider KR, Wethey DS, Helmuth BST, Hilbish TJ. 2005. Implications of movement behavior 760 on mussel dislodgement: exogenous selection in a Mytilus spp. hybrid zone. Marine Biology 761 146:333-343. DOI: 10.1007/s00227-004-1446-z.

762 Seabra R, Wethey DS, Santos AM, Lima FP. 2011. Side matters: Microhabitat influence on 763 intertidal heat stress over a large geographical scale. Journal of Experimental Marine Biology 764 and Ecology 400:200-208. DOI: 10.1016/j.jembe.2011.02.010.

765 Seabra R, Wethey DS, Santos AM, Lima FP. 2015. Understanding complex biogeographic 766 responses to climate change. Scientific Reports 5:12930. DOI: 10.1038/srep12930.

767 Seuront L, Nicastro KR, Zardi GI, Goberville E. 2019. Decreased thermal tolerance under 768 recurrent heat stress conditions explains summer mass mortality of the blue mussel Mytilus 769 edulis. Scientific Reports 9:17498. DOI: 10.1038/s41598-019-53580-w.

770 Seed, R. 1976: Ecology. In B. L. Bayne (ed.): Marine mussels: their ecology and physiology. Pp. 771 13-65. Cambridge: Cambridge University Press.

772 Simon A, Arbiol C, Nielsen EE, Couteau J, Sussarellu R, Burgeot T, Bernard I, Coolen JWP, 773 Lamy J-B, Robert S, Skazina M, Strelkov P, Queiroga H, Cancio I, Welch JJ, Viard F, Bierne N. 774 2020. Replicated anthropogenic hybridisations reveal parallel patterns of admixture in marine 775 mussels. Evolutionary Applications 13:575-599. DOI: 10.1111/eva.12879.

776 Somers IF. 1988. On a seasonally oscillating growth function. Fishbyte 6(1), 8-11.

777 Sukhotin AA, Flyachinskaya LP. 2009. Aging reduces reproductive success in mussels Mytilus 778 edulis. Mechanisms of Ageing and Development 130:754-761. DOI: 10.1016/j.mad.2009.09.005.

779 Taylor MH, Mildenberger TK. 2017. Extending electronic length frequency analysis in R.

780 Fisheries Management and Ecology 24:330-338. DOI: https://doi.org/10.1111/fme.12232.

781 Thomas Y, Razafimahefa NR, Ménesguen A, Bacher C. 2020. Multi-scale interaction processes 782 modulate the population response of a benthic species to global warming. Ecological Modelling 783 436:109295. DOI: 10.1016/j.ecolmodel.2020.109295.

784 Thorarinsdóttir GG, Gunnarsson K. 2003. Reproductive cycles of Mytilus edulis L. on the west 785 and east coasts of Iceland. Polar Research 22:217-223. DOI: 10.3402/polar.v22i2.6456.

786 Toro JE, Thompson RJ, Innes DJ. 2002. Reproductive isolation and reproductive output in two 787 sympatric mussel species (Mytilus edulis, M. trossulus) and their hybrids from Newfoundland. 788 Marine Biology 141:897-909. DOI: 10.1007/s00227-002-0897-3. 
789 Van Haren RJF, Kooijman SALM. 1993. Application of a dynamic energy budget model to

790 Mytilus edulis (L.). Netherlands Journal of Sea Research 31:119-133. DOI: 10.1016/0077-

791 7579(93)90002-A.

792 van der Veer HW, Cardoso JFMF, van der Meer J. 2006. The estimation of DEB parameters for

793 various Northeast Atlantic bivalve species. Journal of Sea Research 56:107-124. DOI:

794 10.1016/j.seares.2006.03.005.

795 Wang H-Y, Tsang LM, Lima FP, Seabra R, Ganmanee M, Williams GA, Chan BKK. 2020.

796 Spatial Variation in Thermal Stress Experienced by Barnacles on Rocky Shores: The Interplay

797 Between Geographic Variation, Tidal Cycles and Microhabitat Temperatures. Frontiers in

798 Marine Science 7. DOI: 10.3389/fmars.2020.00553

799 Zardi GI, Nicastro KR, McQuaid CD, de Jager M, van de Koppel J, Seuront L. 2021. Density-

800 Dependent and Species-Specific Effects on Self-Organization Modulate the Resistance of Mussel

801 Bed Ecosystems to Hydrodynamic Stress. The American Naturalist 197:615-623. DOI:

$80210.1086 / 713738$. 
Figure 1

Study site at Le Petit Minou, Plouzané, France.

The "West" and "East" correspond to the rocky shore sampling areas to the left and right sides of the beach, respectively.

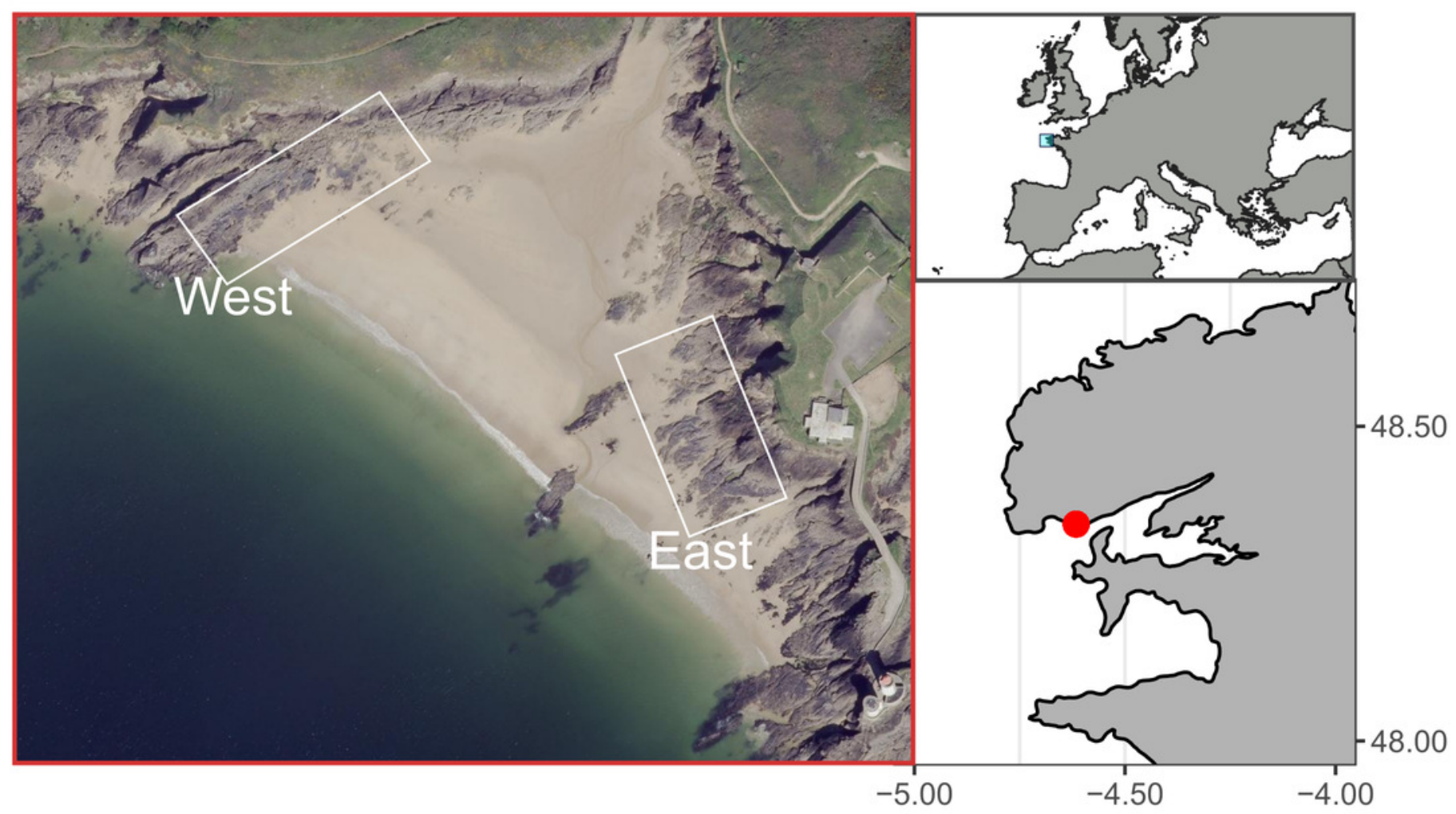




\section{Figure 2}

Schematic representation of the degree of crowding in a patch of individuals as the ratio between the observed covered area and the total basal covered area.

The basal covered area corresponds to the projected vertical shadow of the individuals, represented in blue. A perfect equivalence between these areas (grey line) corresponds to a crowding index value of one, when there is no overlap between basal areas. Very crowded patches have a high overlap of the individual basal areas (A), whereas in less crowded patches there is more space between individual basal areas (B). The crowding index takes values $>1$ in case $A$ and $<1$ in case $B$.

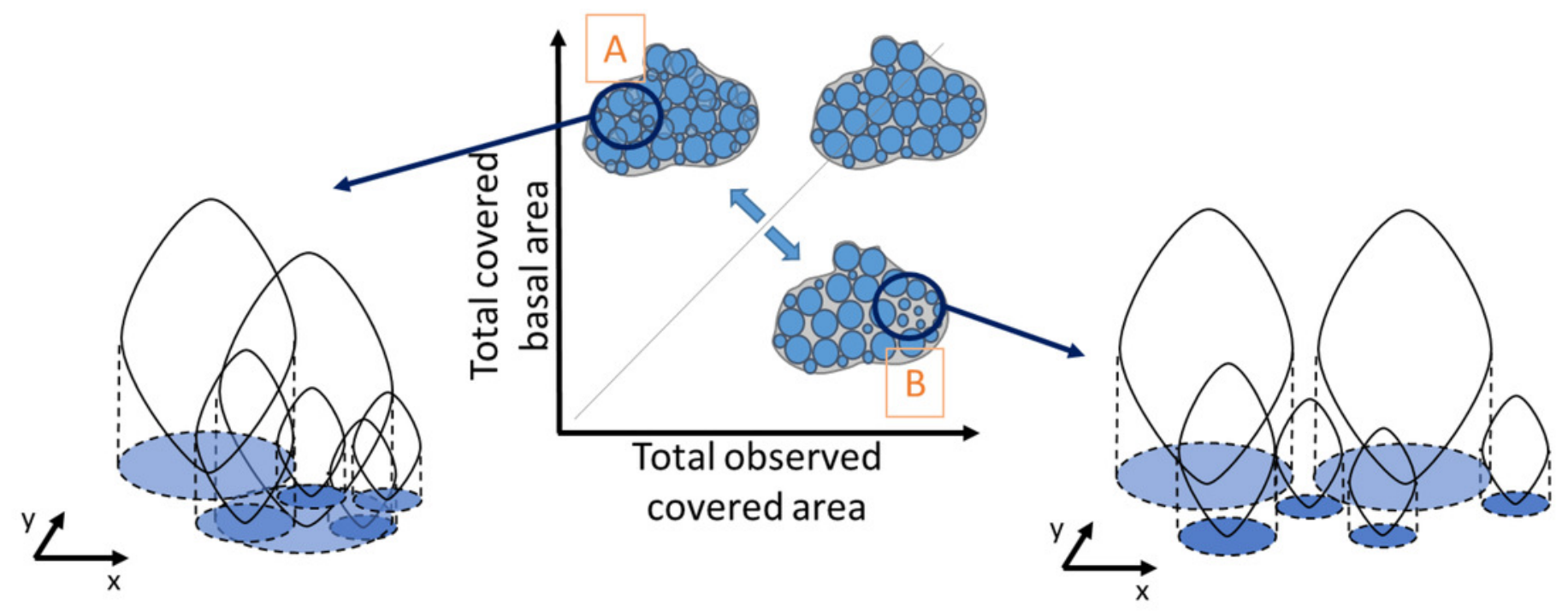




\section{Figure 3}

Percentage immersion time (\%; left $y$ axis) and intertidal height ( $m$ above LAT; right $y$ axis) of quadrat samples on the West and East shores of Le Petit Minou.

The lower and upper hinges of the boxplots correspond to the first and third quantiles, the middle line corresponds to the mean value, and whiskers (vertical lines) indicate the highest and smallest values (between $1.5 *$ the interquartile range (IQR)). Each point corresponds to one quadrant sample. 


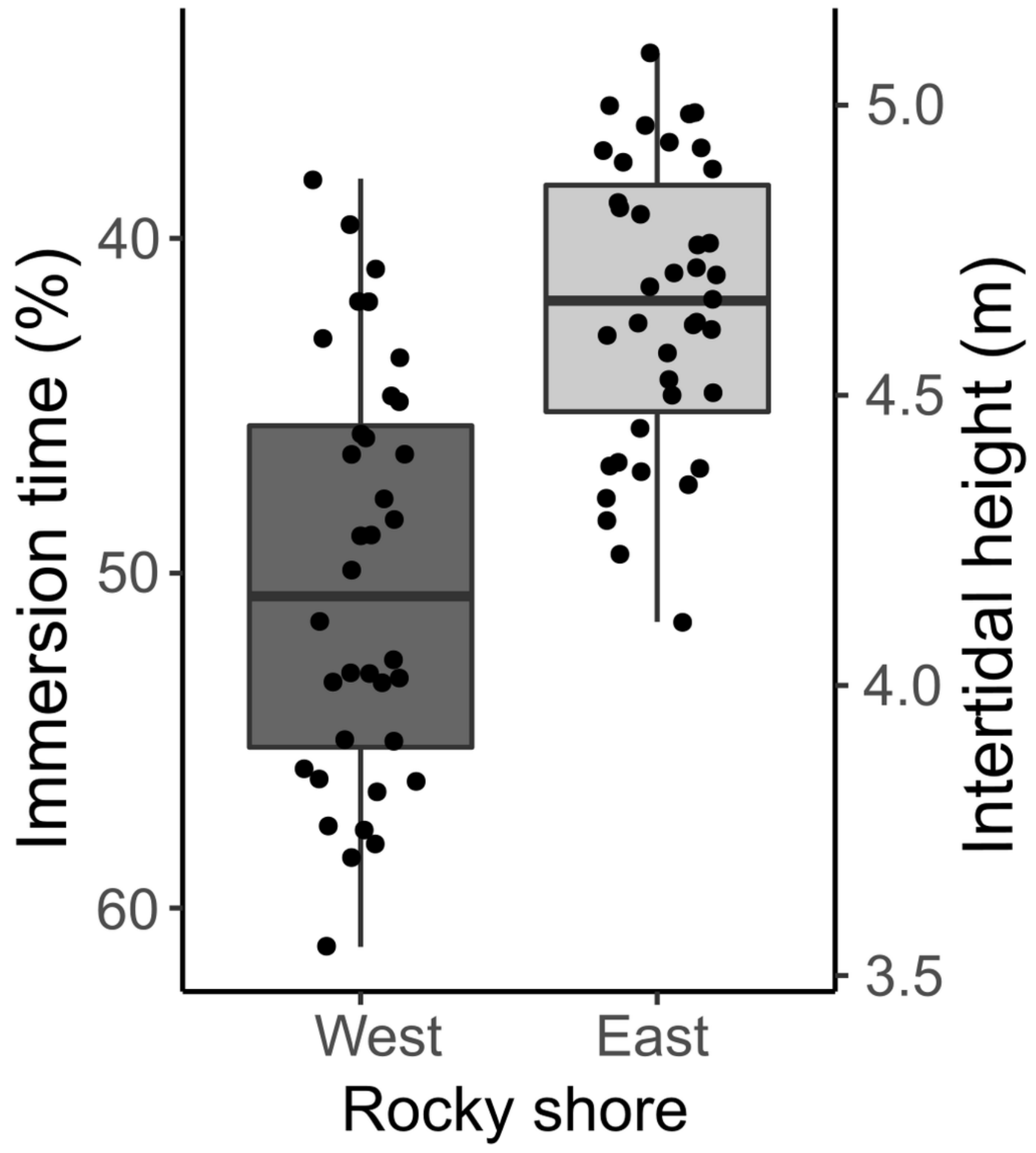




\section{Figure 4}

Annual variation in individual condition index (A), the proportion of individuals at the spawning stage (B), and the recruit density (ind. $\mathrm{m}^{-2}$.month) on the West (dark grey) and East (light grey) shores of Le Petit Minou (C).

On (A) panel, the boxplots represent the range between the first and third quantiles and the mean value, with the highest and smallest values (between $1.5 *$ the interquartile range (IQR)) indicated by the whiskers and individual points represent outliers. On (B) panel, * indicates significant differences between West and East shores $(p<0.05)$. On (C) panel, barplots represent the mean and standard deviation (SD) of each month and shore. Different letters indicate significantly different groups $(p<0.05)$. 


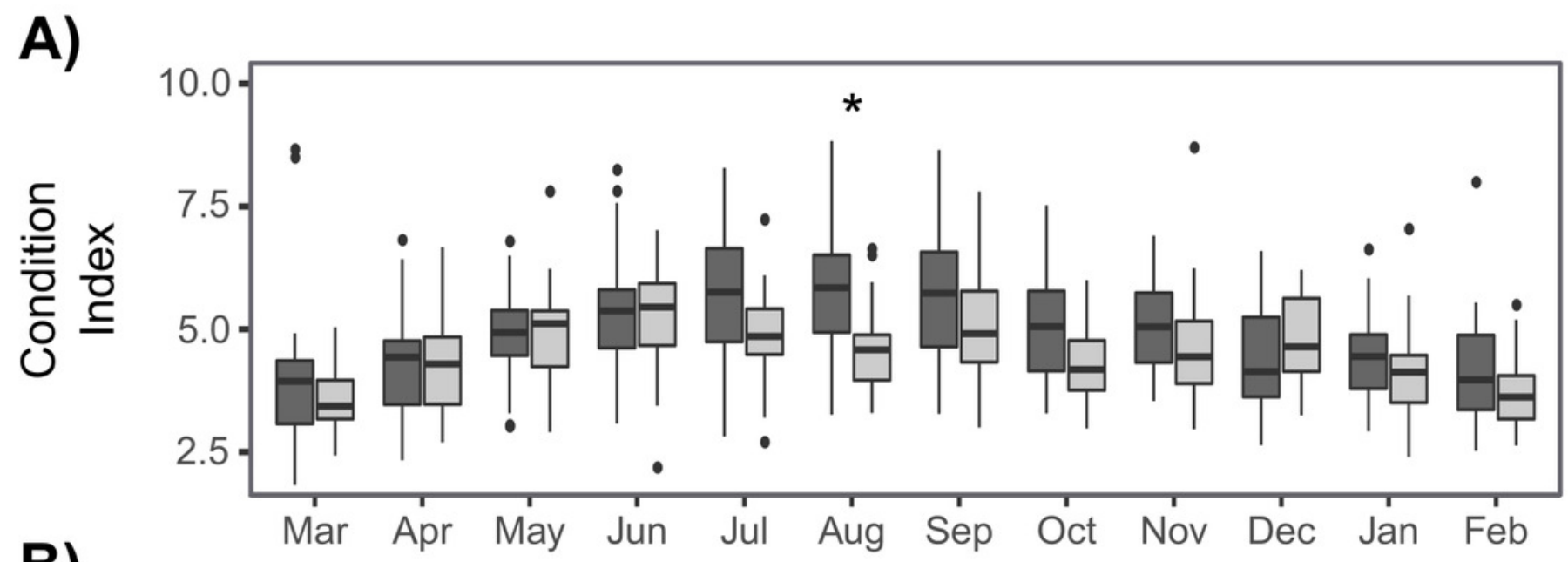

B)

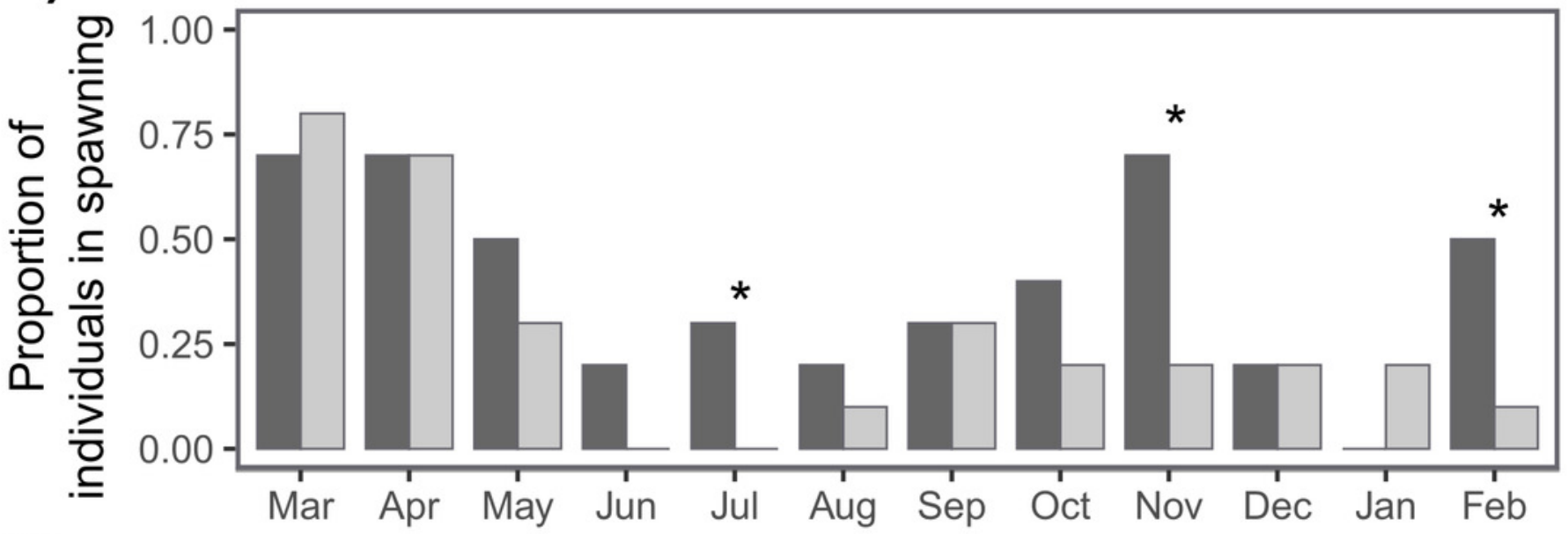

C)

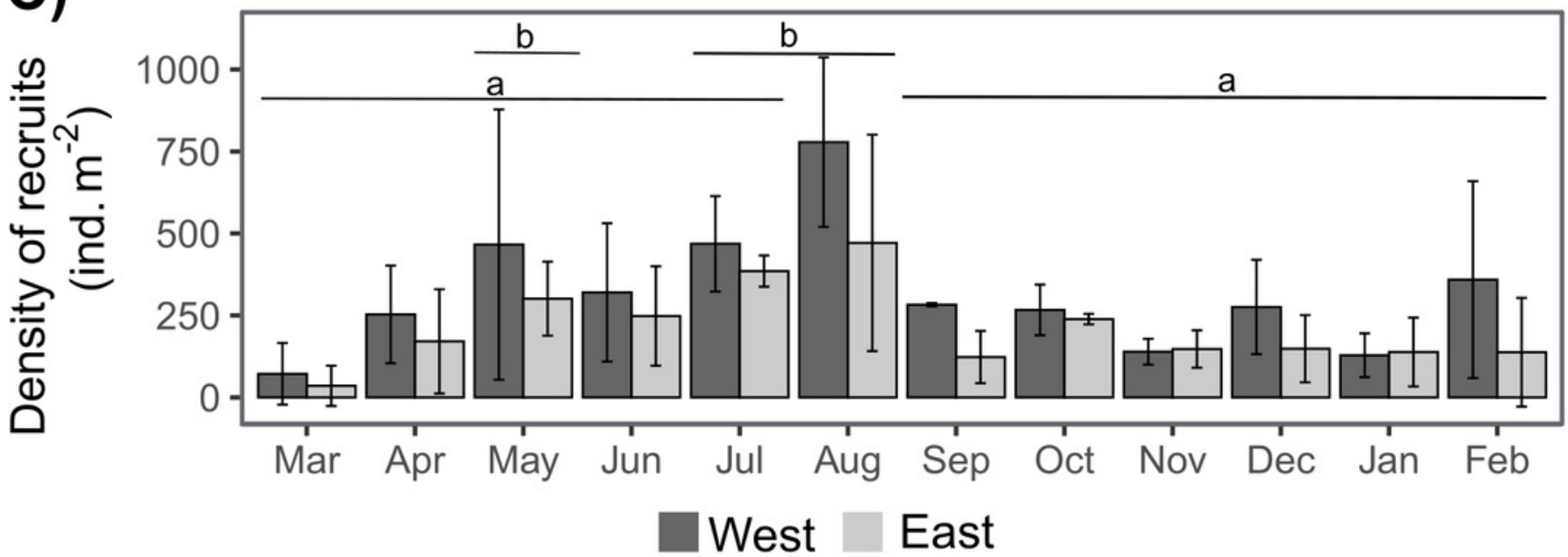




\section{Figure 5}

Relationship between the recruitment density and adult density in the West (dark grey) and East (light grey) shores of Le Petit Minou.

Dots represent the data from West (dark grey) and East (light grey) shores at Le Petit Minou. The trend on each shore is represented by the lines; there is no significant difference in the slope of the regression lines (no significant interaction, for more details, see Table 2 and Table S3). 


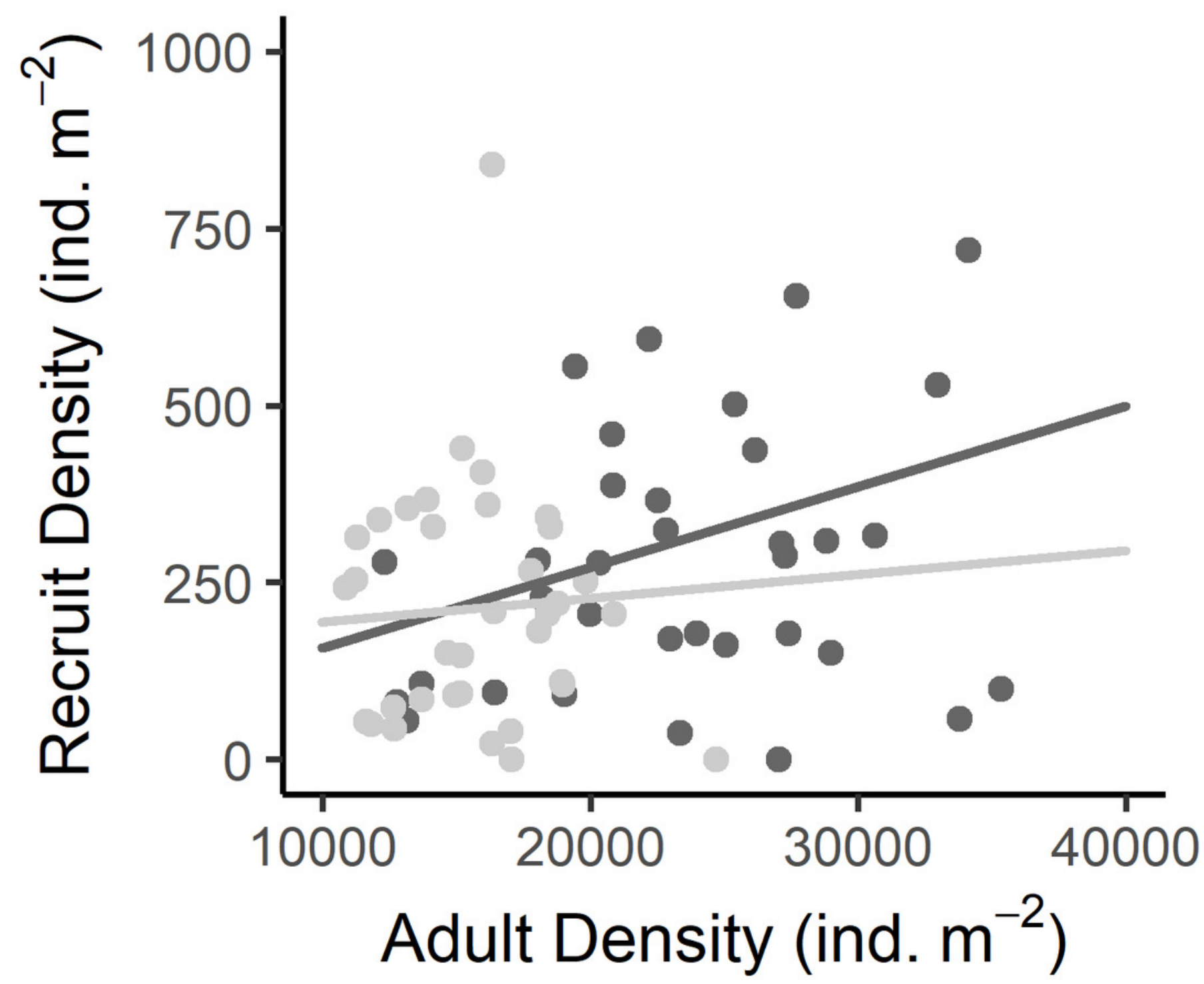




\section{Figure 6}

Estimated von Bertalanffy growth curves observed age-at-length data (circles) showing the concordance between estimations and observations.

The von Bertalanffy curves have been estimated based on the size distribution of all sampled individuals from the West (dark grey) and East (light grey) shores of Le Petit Minou using the ELEFAN_GA approach. Age-at-length data was determined by sclerochronology analysis. Dark grey and light grey circles correspond to the age at length (only the last growth mark was considered) of individuals from the West and East shore ( $n=17$; from each shore), respectively. 


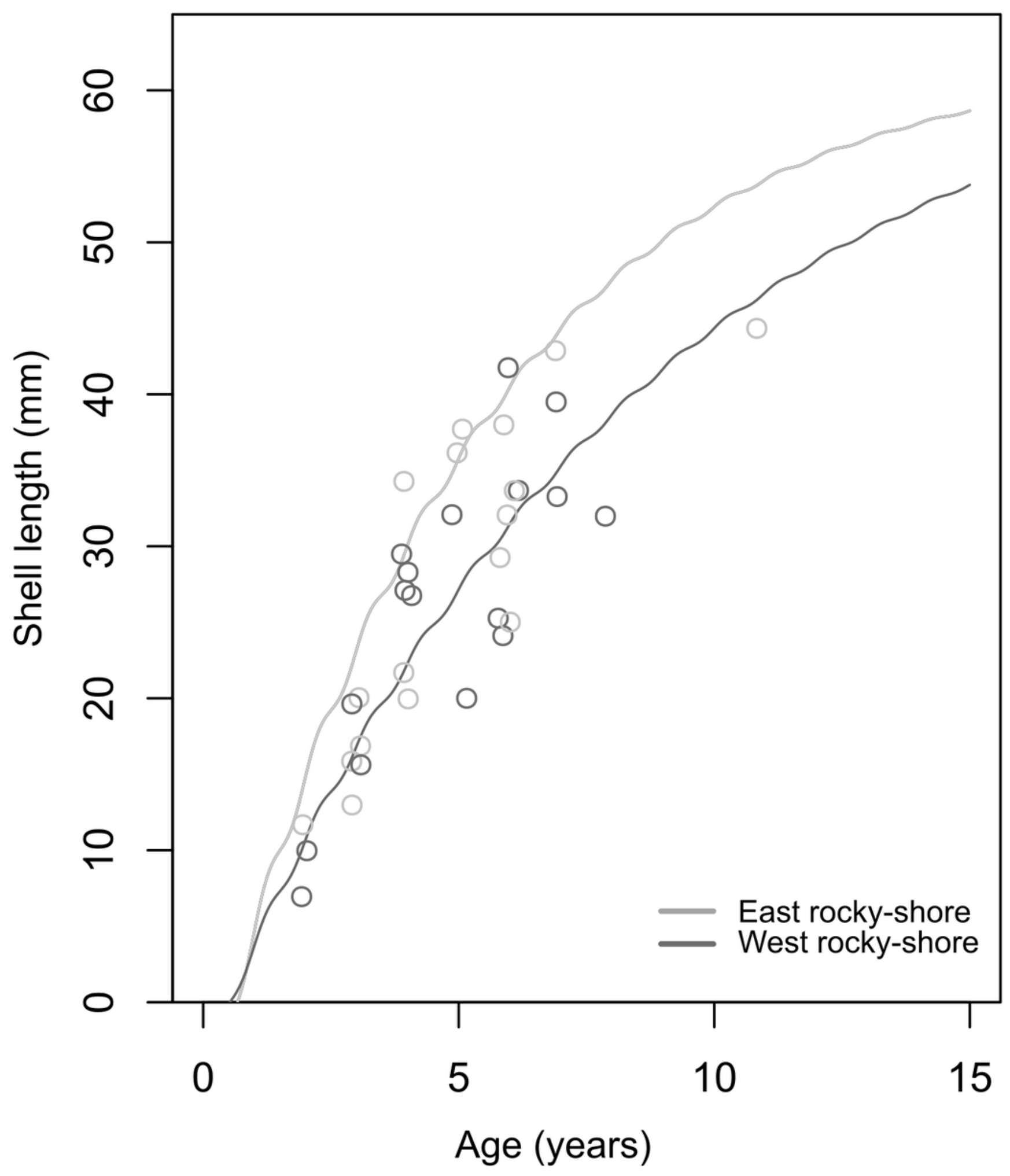




\section{Figure 7}

Relationship between instantaneous mortality rate $(\mathrm{Z})$ and the intertidal height ( $\mathrm{m}$ above LAT) of samples on the West (dark grey) and East (light grey) shores of Le Petit Minou.

Lines represent the relationship determined by a general linear model (for more details, see Table 2 and Table S3) and dots represent the data from West (dark grey) and East (light

grey) shores at Le Petit Minou. Significant difference between shores is indicated: *rocky shore. 


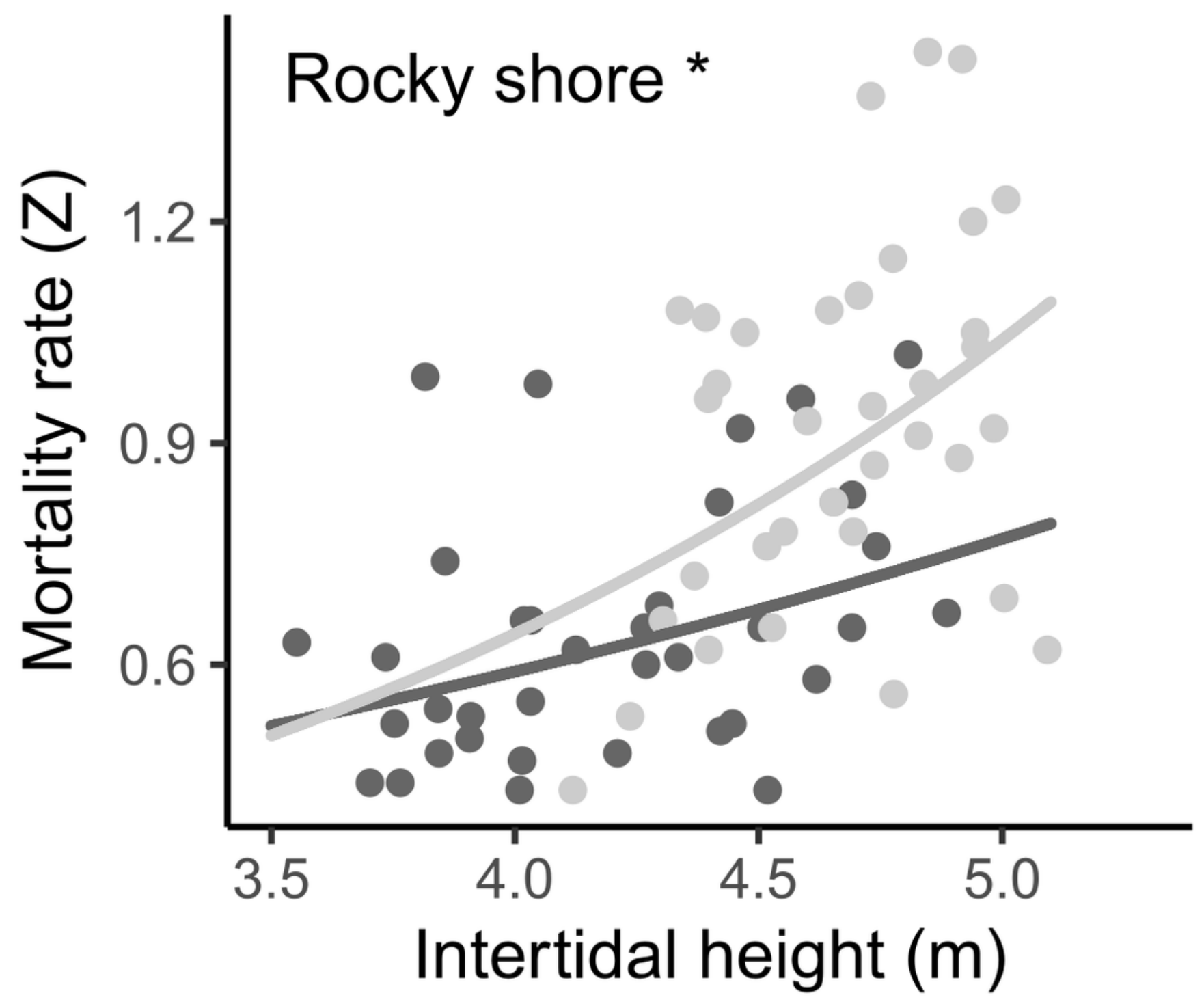




\section{Figure 8}

Relationships between intertidal height and population variables: (A) biomass, (B) density, (C) median length, (D) maximal length, and (E) crowding index. (F) Relationship of the crowding index with the median length and density of individuals.

Dots represent the data from West (dark grey) and East (light grey) shores at Le Petit Minou; one for each sample $(n=720)$. The trends on each shore are represented by the lines in the cases of significant relationships; significant differences between shores are indicated *rocky shore on the plots; there are no significant differences in the slope of the regression lines in each plot (no significant interaction, for more details, see Table 2 and Table S3). Median length and maximal length were calculated from a variable number of individuals, which corresponded to the total of individuals in the sample excluding recruits (data available in the supplementary material). In panel (F) the surface layer represents the trend of crowding index depending on the density and median length, and each pair-variables relationship is represented by the projected shadow of observation into each axis (dots). 

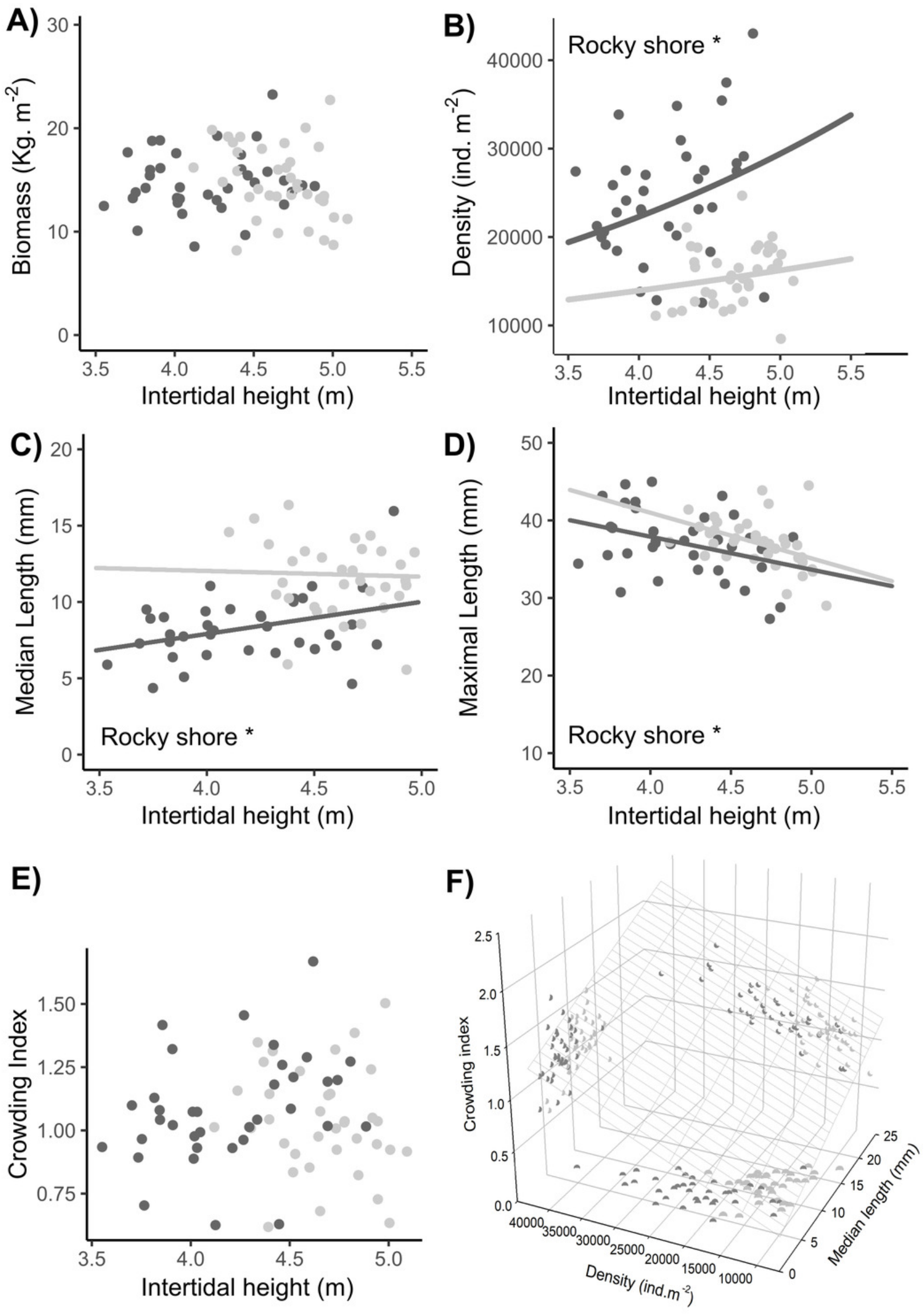
Figure 9

Simulated reproductive output of the mussels in the West and East shores of Le Petit Minou.

Data are shown relative to the population size structure (bars) and cumulated (curve), for the reproductively mature individuals (i.e., length $>12 \mathrm{~mm}$ ).
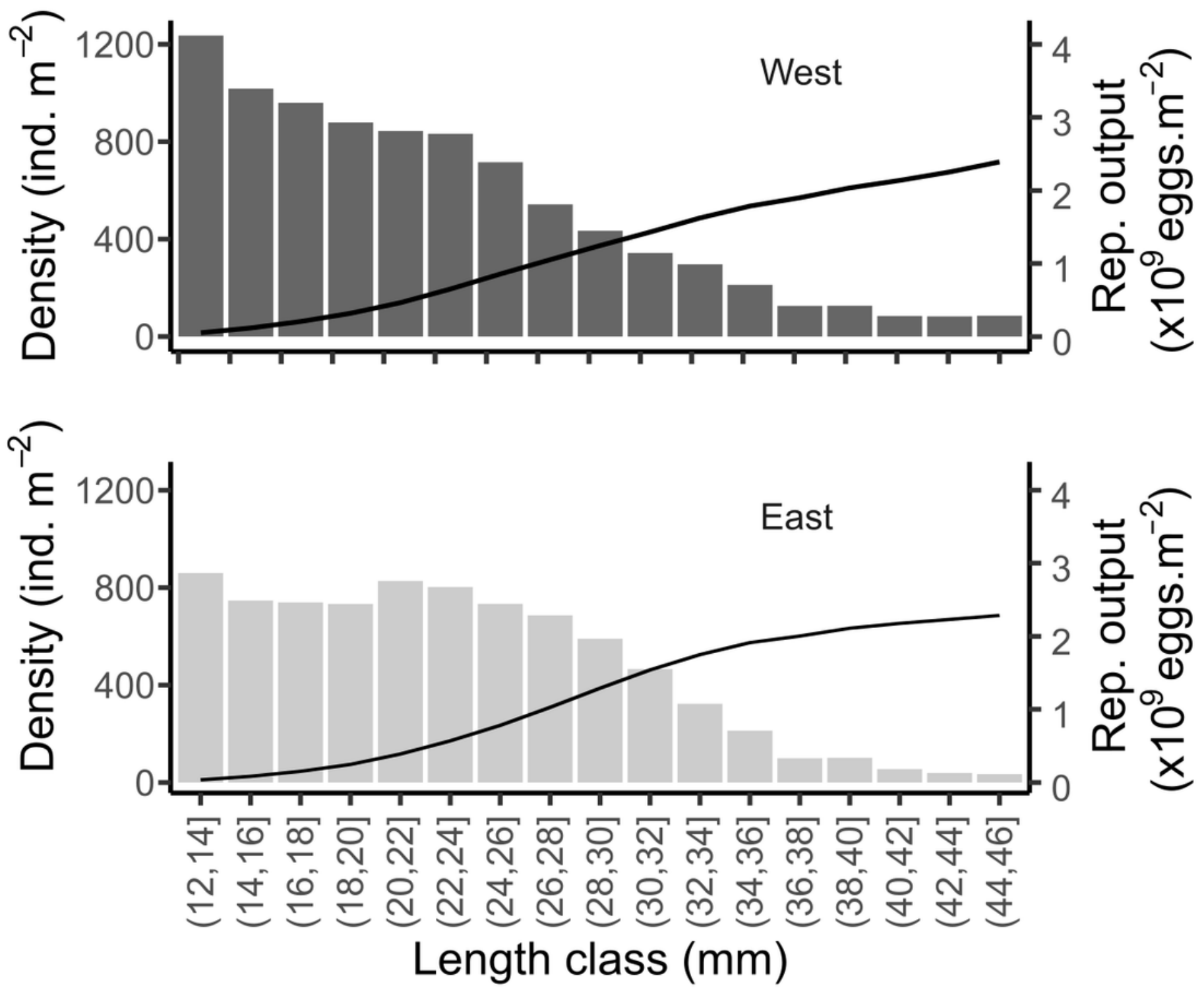


\section{Table $\mathbf{1}$ (on next page)}

Statistical analyses evaluating the shore, date and intertidal height above LAT effect on variables at individual and population scales.

The statistical analysis used is specified in the "Analysis method" column. * indicates significance and n.s. indicates non significance. 


\begin{tabular}{|c|c|c|c|c|c|c|}
\hline & \multicolumn{3}{|c|}{ Independent variables } & \multicolumn{2}{|l|}{ Interactions } & \multirow{2}{*}{$\begin{array}{l}\text { Analysis } \\
\text { method }\end{array}$} \\
\hline & Shore & Date & $\begin{array}{l}\text { Intertidal } \\
\text { height }\end{array}$ & Date*Shore & $\begin{array}{l}\text { Intertidal } \\
\text { height*Shore }\end{array}$ & \\
\hline Biomass & n.s. & n.s. & n.s. & n.s. & $*$ & LM \\
\hline $\begin{array}{l}\log _{10}(\text { Densit } \\
y)\end{array}$ & $\begin{array}{l}3.66 \mathrm{e}- \\
08^{*}\end{array}$ & n.s. & $0.0083^{*}$ & n.s. & n.s. & LM \\
\hline $\begin{array}{l}\text { Max. } \\
\text { Length }\end{array}$ & $\begin{array}{l}0.0388 \\
8 *\end{array}$ & n.s. & $0.0081^{*}$ & n.s. & n.s. & $\mathrm{LM}$ \\
\hline $\begin{array}{l}\text { Median } \\
\text { Length } \\
\text { (excluding } \\
\text { recruits) }\end{array}$ & $\begin{array}{l}0.0001 \\
*\end{array}$ & & $<0.0001^{*}$ & & n.s & $\begin{array}{l}\text { LMM; } \\
\text { random } \\
\text { factor: Date }\end{array}$ \\
\hline $\begin{array}{l}\text { Condition } \\
\text { Index }\end{array}$ & $\begin{array}{l}1.013 \mathrm{e}- \\
06^{*}\end{array}$ & $\begin{array}{l}<2.2 \mathrm{e}- \\
16^{*}\end{array}$ & n.s. & $0.01575^{*}$ & n.s. & $\begin{array}{l}\text { GLM } \\
\text { (family= } \\
\text { gamma, } \\
\text { link= log) }\end{array}$ \\
\hline $\begin{array}{l}\text { Crowding } \\
\text { Index }\end{array}$ & n.s. & n.s. & n.s. & n.s. & n.s. & $\mathrm{LM}$ \\
\hline
\end{tabular}

\section{Crowding}

Index

\begin{tabular}{lllll}
\hline & Shore & Adult density & $\begin{array}{l}\text { Median } \\
\text { Length }\end{array}$ & \\
\hline $\begin{array}{l}\text { Crowding } \\
\text { index }\end{array}$ & n.s. & $<0.0001^{*}$ & $<0.0001^{*}$ & $\begin{array}{l}\text { LMM; } \\
\text { random } \\
\text { factor: Date }\end{array}$ \\
\hline
\end{tabular}

\section{Recruitmen}

t

Shore Date Adult density Date*Shore $\begin{aligned} & \begin{array}{l}\text { Adult } \\ \text { density*Shore }\end{array} \\ & \begin{array}{l}\text { Intertidal } \\ \text { height }\end{array}\end{aligned}$




$\begin{array}{lllllll}\begin{array}{l}\text { Recruit } \\ \text { density }\end{array} & \text { n.s. } & 0.0007 * & 0.0001 * & \text { n.s. } & \text { n.s. } & \text { n.s. }\end{array}$

1 


\section{Table 2 (on next page)}

Statistical significance of the effects of shore and intertidal height above LAT on mortality rate $(Z)$.

Results according to a linear mixed model (LMM) with date as random factor. $*$ indicates significance and n.s. indicates non significance. 
Mortality rate

(LMM)

\begin{tabular}{llll}
\hline & Shore & Intertidal height & $\begin{array}{l}\text { Intertidal height } \\
* \text { Shore }\end{array}$ \\
\hline $\begin{array}{l}\log _{10}(\text { Mortality } \\
\text { rate, } \mathbf{Z})\end{array}$ & $0.0103 *$ & $<0.0001 * * *$ & n.s. \\
\hline
\end{tabular}

1 